Elizabeth Kelvin

Gavin George

Eva Mwai

Samuel Kinyanjui

Silas Inoti

Faith Oruko

Jacob Odhiambo

Eston Nyaga

Taruna Chetty

et al.
Increasing HIV testing demand among Kenyan truck drivers and female sex workers

May 2019
Impact

Evaluation

Report 98

\section{HIV and AIDS}




\section{About 3ie}

The International Initiative for Impact Evaluation (3ie) promotes evidence-informed equitable, inclusive and sustainable development. We support the generation and effective use of high-quality evidence to inform decision-making and improve the lives of people living in poverty in low- and middle-income countries. We provide guidance and support to produce, synthesize and quality-assure evidence of what works, for whom, how, why and at what cost.

\section{3ie impact evaluations}

3ie-supported impact evaluations assess the difference a development intervention has made to social and economic outcomes. 3ie is committed to funding rigorous evaluations that include a theory-based design, and use the most appropriate mix of methods to capture outcomes and are useful in complex development contexts.

\section{About this report}

3ie accepted the final version of the report, Increasing HIV testing demand among Kenyan truck drivers and female sex workers, as partial fulfilment of requirements under grant TW2.2.06 awarded through the HIV Self-Testing Evidence Programme. The content has been copy-edited and formatted for publication by 3ie.

The 3ie technical quality assurance team for this report comprises Anna C Heard, Eric W Djimeu, Ritwik Sarkar, Nancy Diaz, an anonymous external impact evaluation design expert reviewer and an anonymous external sector expert reviewer, with overall technical supervision by Marie Gaarder. The 3ie editorial production team for this report comprises Sahib Singh and Akarsh Gupta, with Beryl Leach providing overall editorial supervision.

All of the content is the sole responsibility of the authors and does not represent the opinions of 3ie, its donors or its board of commissioners. Any errors and omissions are also the sole responsibility of the authors. All affiliations of the authors listed in the title page are those that were in effect at the time the report was accepted. Please direct any comments or queries to the corresponding author, Elizabeth A Kelvin at elizabethakelvin@gmail.com.

Funding for this impact evaluation was provided by 3ie's donor, the Bill \& Melinda Gates Foundation.

Suggested citation: Kelvin, E, George, G, Mwai, E, Kinyanjui, S, Inoti, S, Chetty, T, Strauss, M, Romo, M, Oruko, F, Odhiambo J, Nyaga, E, Mantell, J and Govender, K, 2019. Increasing HIV testing demand among Kenyan truck drivers and female sex workers, 3ie Impact Evaluation Report 98. New Delhi: International Initiative for Impact Evaluation (3ie). Available at: https://doi.org/10.23846/TW2IE98

Cover photo: Jennifer Huxta

(C) International Initiative for Impact Evaluation (3ie), 2019 
Increasing HIV testing demand among Kenyan truck drivers and female sex workers

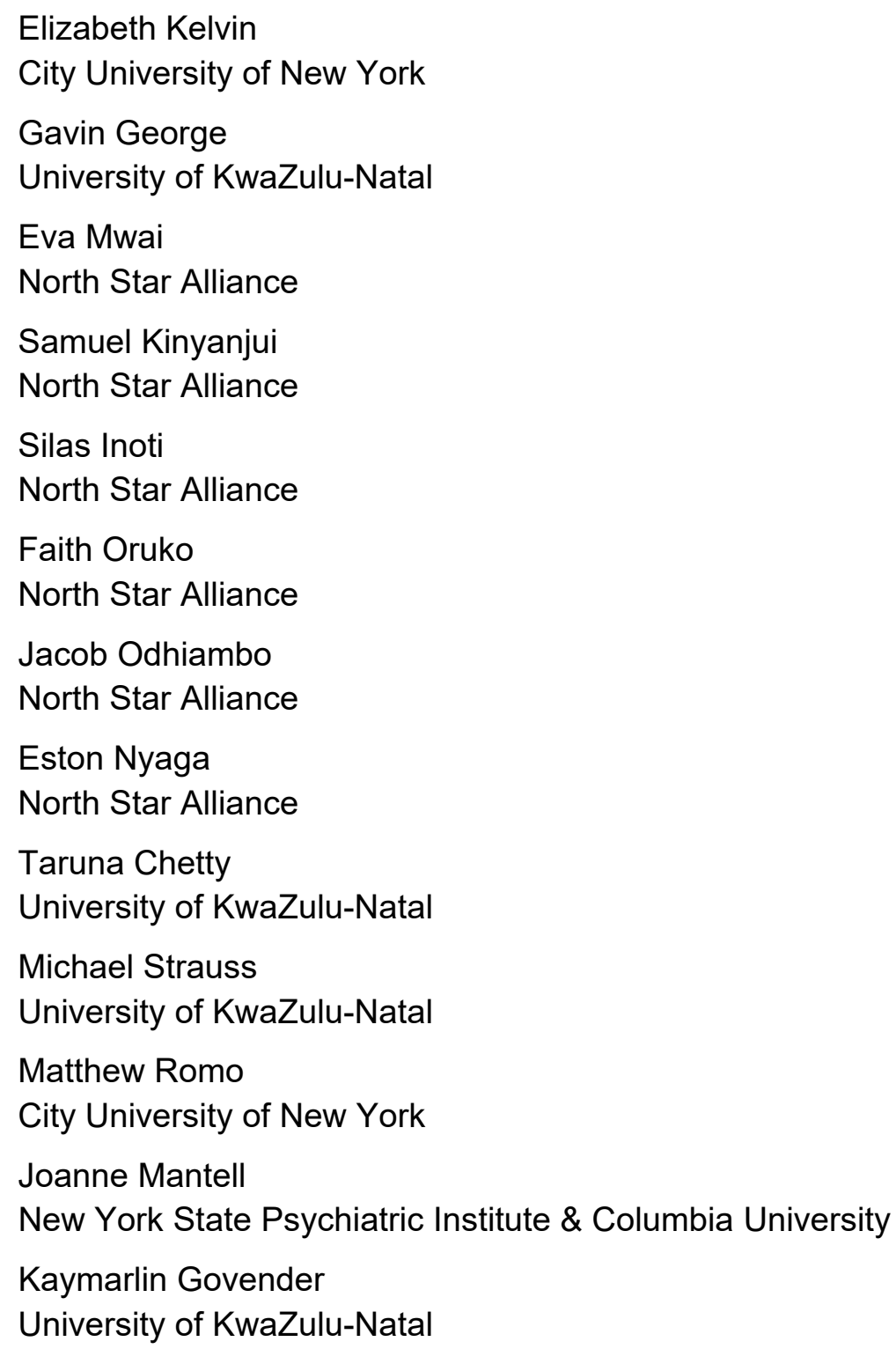

Impact Evaluation Report 98

May 2019

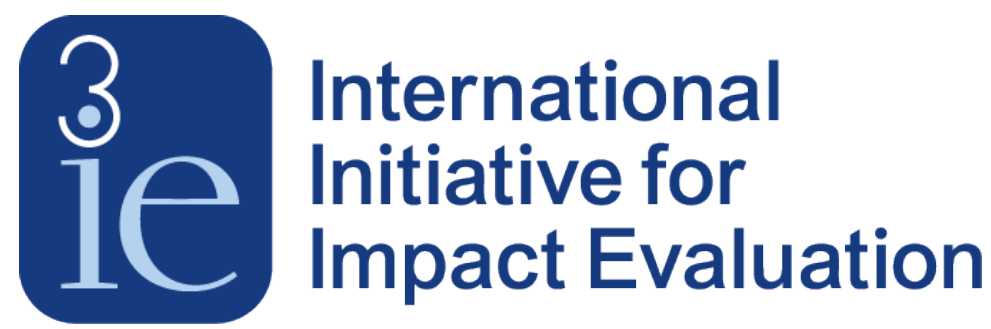




\section{Acknowledgements}

This study was supported by a grant from the International Initiative for Impact Evaluation (3ie \# TW2.2.06 supplement, Kelvin Principal Investigator). Elizabeth Kelvin was also supported by the Einstein-Rockefeller-CUNY Center for AIDS Research [P30Al124414] which is supported by the following National Institutes of Health (NIH) CoFunding and Participating Institutes and Centers: NIAID, NCI, NICHD, NHBL, NIDA, $\mathrm{NIMH}, \mathrm{NIA}, \mathrm{FIC}$ and OAR. Support for Joanne Mantell also came from a center grant from the National Institute of Mental Health (NIMH) to the HIV Center for Clinical and Behavioral Studies at the New York State Psychiatric Institute and Columbia University [P30-MH43520; Principal Investigator: Robert H Remien, PhD].

We want to thank the HTC counselors and clinic staff, especially Deborah Ochungo, Lucy Wanjiru, Oliver Simiyu, Ernest Otieno, Joan Nyaga, Naomi Jepkemei, Charles Kilundo, Hellen Naini, Timothy Rotich, and Irene Marete, who all ensured that the protocol was followed and that self-testers were tracked for follow-up post-test counseling and referrals. We also want to thank the staff at the North Star Alliance Nairobi office, who helped with administrative requirements such as ethics committee applications. Finally, we want to express our appreciation of the North Star Alliance clients who were part of this evaluation. 


\section{Summary}

The objective of this randomized controlled trial was to assess whether making HIV selftest kits available as a testing option at North Star Alliance roadside wellness clinics in Kenya and advertising their availability via SMS (text message) would increase HIV testing rates among truckers and sex workers who were irregular testers, compared with sending text messages about HIV testing in general.

A sample of 2,262 male truckers and 2,196 female sex workers registered in the North Star Alliance electronic medical record system and who, based on these records, were irregular HIV testers were randomized to one of three study arms in which they were sent text messages about the HIV testing available to them at North Star Alliance Kenya clinics.

Specifically, the different arms received a text, either: (1) communicating the availability of HIV self-test kits at all North Star Alliance Kenya clinics, which was sent three times (intervention); (2) about the availability of HIV testing in general at North Star Alliance clinics, sent three times (enhanced standard of care (SOC)); or (3) about HIV testing at North Star Alliance clinics in general, sent once (SOC). When arriving at a North Star Alliance clinic in Kenya, those in the enhanced SOC and SOC groups were only offered one HIV test, the standard provider-administered rapid finger-prick blood HIV test. Those in the intervention group, when arriving in a clinic, were offered a choice between (1) the SOC HIV test; (2) a rapid oral HIV self-test for self-administration in the clinic with supervision; or (3) the rapid oral HIV self-test kit to take for home use with phone-based post-test counseling. We followed each sample for two months and looked at differences in HIV testing using logistic regression.

Truckers and sex workers in the intervention arm were significantly more likely to test for HIV during follow-up compared with those in the enhanced SOC (OR $=2.7, p=0.007$ and $\mathrm{OR}=1.9, p=0.001$ respectively). There was no difference in HIV testing between those in the enhanced SOC and the SOC arms for either sample. The intervention proved to be more cost effective than either the enhanced SOC or the SOC, even though the HIV self-test kits cost much more than the standard provider-administered HIV test because of the higher HIV testing rates in the intervention arm.

Offering HIV self-testing to high-risk populations such as truckers and sex workers and advertising its availability via text message may be a cost-effective way to increase HIV testing rates in these important groups. 


\section{Contents}

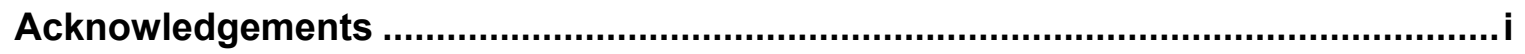

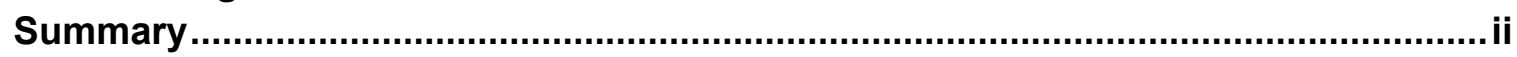

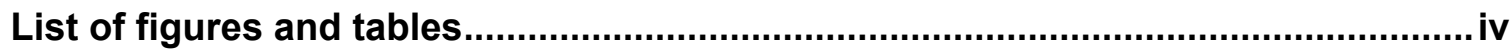

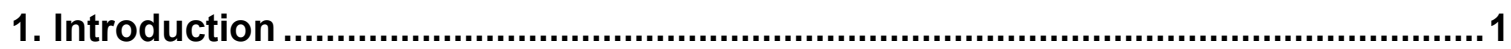

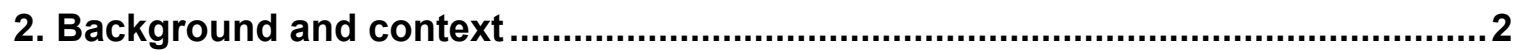

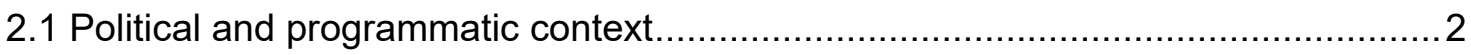

2.2 Theory of change

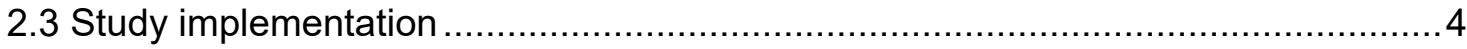

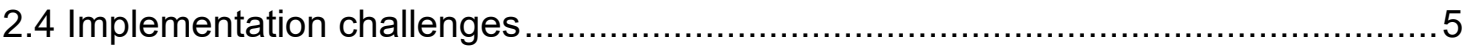

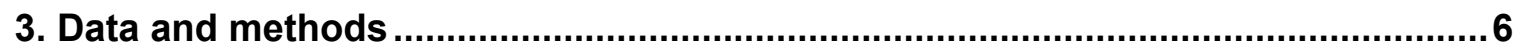

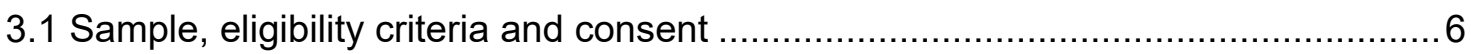

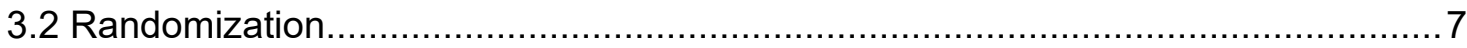

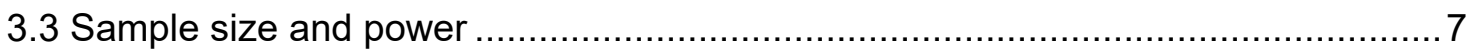

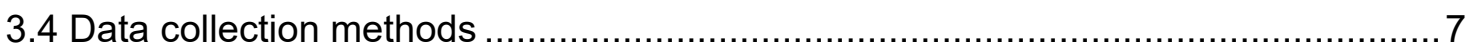

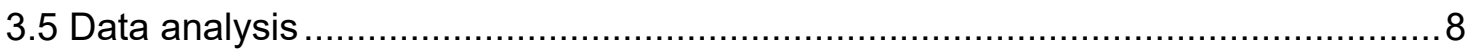

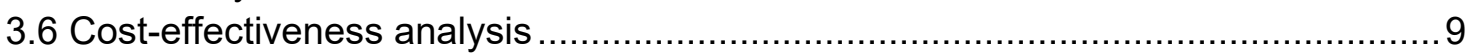

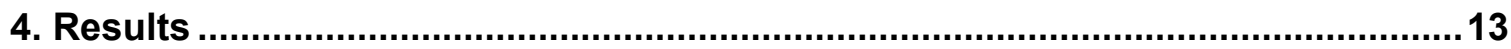

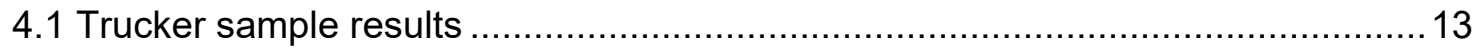

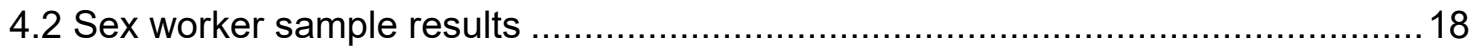

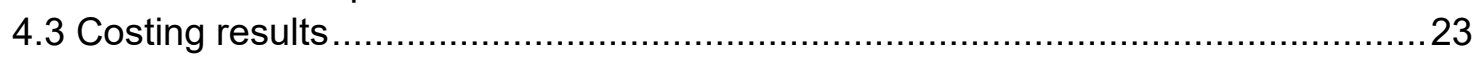

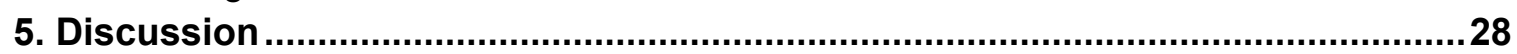

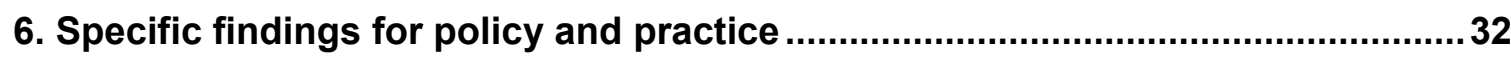

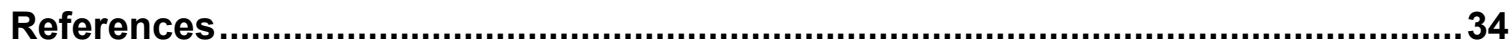




\section{List of figures and tables}

Figure 1: Flow of male truck driver participants (Consort Flowchart) ............................. 14

Figure 2: Flow of female sex worker participants (Consort Flowchart) ........................... 19

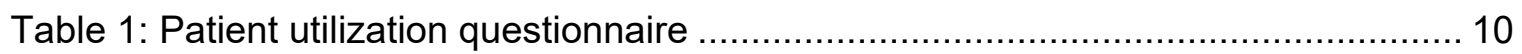

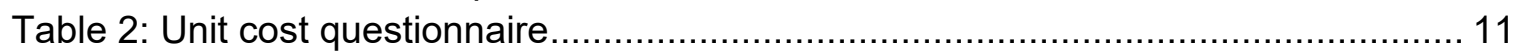

Table 3: Descriptive statistics for the sample overall and by the three study arms......... 15

Table 4: Logistic regression model results for HIV testing and clinic contact comparing the intervention with the enhanced SOC arms ......................................... 16

Table 5: Logistic regression model results for HIV testing and clinic contact comparing the enhanced SOC with the SOC arms................................................... 17

Table 6: description of HIV testing choices made for those in the intervention arm who

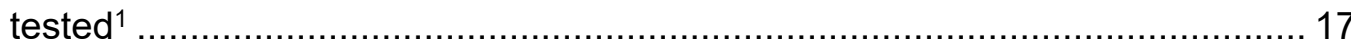

Table 7: Descriptive statistics for female sex worker sample overall and by study arm . 20

Table 8: Looking at differences in HIV testing and in receiving clinic services in general comparing intervention with the enhanced SOC among female sex workers .. 21

Table 9: Looking at differences in HIV testing and in receiving clinic services in general, comparing the enhanced SOC with the traditional SOC .............................. 22

Table 10: Description of self-testing among female sex workers in the intervention group and six not in the sample who requested a self-test ................................... 23

Table 11: Total SMS costs and average SMS cost per client (Activity A) ....................... 24

Table 12: Average cost per HTC and HIV self-test client (activities B, C, D and E) ....... 24

Table 13: Total cost and cost per client by study arm, truck drivers (Activities A-E) ...... 25

Table 14: The ICERs across study arms, truck drivers and female sex workers ............ 26

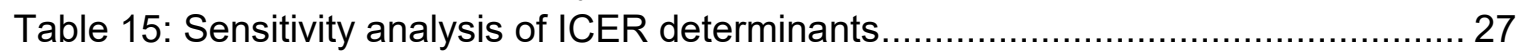

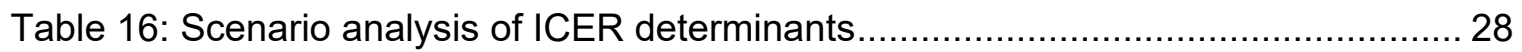




\section{Introduction}

In sub-Saharan Africa, truckers (drivers and assistants) as well as sex workers who provide services at major transport hubs, are at higher risk for HIV compared with those working in other settings (Matama 2013; Ojo et al. 2011). HIV transmission has been associated with migratory labor patterns and transportation routes (Ramjee et al. 1998; Abdool-Karim and Abdool-Karim 2002), and in some areas, including East Africa, HIV rates remain high along border posts and major highways (Matama 2013; FHI 360 2013; Tanser et al. 2000).A 1991 study among truck drivers in Kenya found $18 \%$ tested HIVpositive (Bwayo et al. 1991a); 61\% of the sample reported having visited female sex workers (FSWs) and only 32\% had ever used condoms (Bwayo et al. 1991b). A crosssectional survey of 1,896 long-distance truck drivers in South Africa between 2003 and 2004 found a 26 per cent HIV prevalence with a modest dose-response relationship between time on road and HIV risk (Delany-Moretlwe et al. 2014). Other recent studies among truck drivers in Africa also found high HIV prevalence, including $23 \%$ among those aged 31-40 in Nigeria (Azuonwu et al. 2011) and 15.4\% among those in Mozambique (Frank et al. 2013).

The work-related separation associated with truck driving may lead many to patronize commercial sex services or have multiple non-commercial partnerships along the trucking route. A recent study among 3,805 truckers in Kenya found that $55.9 \%$ had paid for sex in the past 6 months and $46.6 \%$ had a regular partner along their trucking route in addition to a wife or girlfriend at home (Kelvin et al. 2017a; b).

HIV prevalence is often higher among FSWs compared with the general population, making the use of commercial sex services a risk factor for infection. In Kenya, for example, about $30 \%$ of sex workers were HIV-positive in 2013 , compared with $5.4 \%$ of the population as a whole (National AIDS Control Council of Kenya (NASCOP) 2014; Musyoki et al. 2015). Because of their complex sexual networks, truckers can be a conduit for the spread of HIV across partner types (commercial, regular partners on their trucking route, wives or girlfriends at home) as well as across national and international borders (IRIN 2013a, International Labor Organization 2005).

HIV testing among truck drivers and sex workers remains suboptimal. Few studies have looked at HIV testing among truck drivers, but one study among 1,881 truck drivers in South Africa in 2003-2004 found that only 38.2 per cent had ever been tested for HIV (Delany-Moretlwe et al. 2014). Testing among FSWs is higher, but given their risk it is also lower than ideal. In Kenya in 2013, 68.0 per cent of FSWs had taken an HIV test in the past 12 months (NASCOP 2014).

HIV self-testing may increase HIV testing rates among key populations such as truckers and sex workers. A number of studies have found that offering HIV self-testing as an option increases HIV test uptake over the standard of care (SOC). A study in Kenya gave pregnant women recruited from antenatal care clinics self-test kits to take home and give to their partners. The proportion of male partners who tested was 1.6 times higher among those in the intervention compared with those partners in the SOC arm in which they were given an invitation card to come to the clinic for HIV testing (Masters et al. 2016). A study among FSWs in Zambia found higher testing rates when self-tests were distributed via community health workers versus the standard care (health workers 
give information about where to access clinic-based testing), but the difference was of borderline significance ( $84.1 \%$ versus $75.1 \%$ testing, $p=0.11$ ) (Chanda et al. 2017). A similar study in Uganda, however, found a significant difference ( $9 \%$ tested in the SOC arm versus $59.5 \%$ in the intervention arm, $p=0.04$ ) (Ortblad et al. 2017).

We conducted a randomized controlled trial (RCT) in 2015 among 305 truckers, looking at whether offering HIV oral self-testing as a choice to truck drivers (versus the SOC to offer only the blood-based provider-administered test) would increase HIV testing. Truckers were recruited from the waiting rooms of two roadside wellness clinics in Kenya, randomized to the intervention or SOC and offered HIV testing as indicated by their study arm before they left the clinic (first offer of testing). In addition, those in the intervention arm were informed that they could pick up self-test kits 3-6 months later and testing during follow-up was examined (second offer of testing).

HIV testing rates were significantly higher in the intervention group at the first offer of testing (OR $=2.8, p=0.002)$ (Kelvin et al. 2017a; b), but there was no difference during the six-month follow-up $(O R=1.0, p=0.972)$ (Kelvin et al. 2017a).

There are a number of possible explanations for these findings, including (1) the self-test may increase testing once someone is in the clinic where they can obtain a test kit (as was the case at the first offer of testing), but it is not sufficient motivation to bring people to the clinic to get a test kit (as was the case for the second offer of testing during followup). Another reason might be (2) since HIV testing rates and frequency were high in this sample (92\% had HIV tested at some time in the past and the median time since last test was 6 months) and a high proportion tested at the first offer of testing $(72.9 \%$ in SOC and $87.3 \%$ in intervention groups), few participants may have felt they needed another test by the six-month follow-up, thus maybe self-testing would have a greater impact among non-regular or infrequent testers. In fact, only 57 participants who completed follow-up had not tested at the first HIV test offer and while they were more likely to test over follow-up (63.4\% versus $54.2 \%$ of those who had tested, $p=0.236)$, the difference was not statistically significant, likely due to the small number (Kelvin et al. 2017a).

In an attempt to address some of these questions, we conducted an RCT among samples of truckers and FSWs who were irregular HIV testers. We aimed to assess whether advertising the availability of HIV self-test kits at clinics via SMS (text message) would bring more people to the participating clinics for HIV testing compared with the SOC text message reminder to test for HIV in general.

\section{Background and context}

\subsection{Political and programmatic context}

The Kenyan government called for oral HIV self-testing to form part of the HIV testing and counseling policy in 2008 (NASCOP 2008) and, in fact, since our study was completed the country has approved self-test kits for sale in pharmacies (World Health Organization (WHO) 2017). Results from this study can help inform the expansion of HIV self-testing in the country, especially clinic-based self-testing programs.

This study was conducted in eight North Star Alliance clinics in Kenya. The North Star Alliance is an international NGO that brings health services to hard-to-reach populations 
across Africa, including truck drivers and sex workers. It runs 38 clinics in 11 countries in Africa, 8 of which are in Kenya. The clinics are open at hours that suit these target groups and offer a range of prevention and treatment services, including: primary healthcare; sexually transmitted infection screening and treatment; tuberculosis screening and treatment; treatment of mobility-related illnesses; behavior change communication; HIV counseling and testing; and, in some clinics, antiretroviral therapy for those who are HIV-positive and laboratory services (North Star Alliance 2014).

In 2016, the North Star Alliance served 207,038 client visits throughout Africa (North Star Alliance 2014). In 2015, 18\% of client visits at North Star Alliance clinics included HIV testing, while $33 \%$ were for primary healthcare, and $46 \%$ for educational sessions and behavioral change counseling. The North Star Alliance clinic system is cited as one of the most successful health interventions in the transport sector (Regondi et al. 2013).

\subsection{Theory of change}

Our hypothesis that HIV testing rates among truck drivers and FSWs would increase when they were informed, via text message in this case, that they had a new HIV testing option, specifically HIV self-testing, is based on prospect theory (Tversky and Kahneman 1981). Prospect theory is an expansion of behavioral economics that considers the certainty of various potential outcomes based on a cost-benefit analysis of the individual situation. However, this theory posits that losses hurt more than gains.

Prospect theory suggests that the barriers to HIV testing that can lead to losses (time, financial and potential social costs associated with the healthcare provider-administered, clinic-based testing available) must be weighed against the benefits of knowing one's status to prevent HIV if one is HIV-negative and prevent transmission to others if one is HIV-positive, and of obtaining appropriate healthcare if one is HIV-positive to improve or maintain health and reduce mortality risk. Further, those potential losses may prevent accessing HIV testing even if their probability of occurrence is lower than the probability of the benefits because many people put more weight on potential negative outcomes in their decision-making process. Thus, interventions that reduce the probability of the potential costs associated with HIV testing should increase the seeking or acceptance of testing.

Oral HIV self-testing as a choice may address some of the risks associated with testing that prevent some individuals from choosing to test under the current system, such as by increasing privacy (thus decreasing the potential social costs) and decreasing the time spent in the clinic for those taking test kits for home use. Thus, self-testing may decrease the barriers currently preventing some truck drivers and FSWs from seeing the benefits of HIV testing.

For some who are already accessing HIV testing under the current program (provideradministered blood test), it is possible that self-testing will have a more positive costbenefit ratio as it addresses the probability of risk, which may be weighed more strongly in decision-making than the benefits, and those individuals may switch to the self-test when given a choice. For others, the cost-benefit ratio may be better for the provideradministered blood test if the perception of risk associated with the self-test is greater than that associated with the standard test (e.g. if they are more concerned that privacy 
will be breached because someone will see them with the test kit rather than a breach due to being seen or overheard at the clinic). The cost-benefit ratio is affected by context and individual preferences and concerns. Offering choices in HIV testing, including a self-testing option, should therefore be more likely to provide an acceptable option than offering only one HIV testing method.

\subsection{Study implementation}

The study was conducted in the eight North Star Alliance clinics in Kenya among two different samples, one with male truckers and one with FSWs. When a person comes to any North Star Alliance clinic, his/her information is entered into the electronic medical record system, including a cell (mobile) phone number if the client has one and is willing to share it. Once registered, information about any additional contacts the client has with the North Star Alliance clinic system is entered into the medical record system.

\subsubsection{HIV testing standard of care}

At every client encounter in a North Star Alliance clinic, HIV testing is offered and the test used is a blood-based (finger-prick) provider-administered test. HIV testing by clients at North Star Alliance clinics is tracked in the electronic medical record system and a few times a year a text message reminder is sent to those clients who do not have a record of HIV testing in the past three months. The message for East Africa clients reads "North Star Alliance East Africa would wish to kindly remind you to visit any of our roadside wellness centres for HIV testing. Your health, our priority." Other health-related text messages are also sent to individuals if they have an appointment or are due for some other test or treatment and this is client specific (so sent occasionally when appropriate); and messages are sent when there is a public health situation that people should know about (e.g. a disease outbreak).

\subsubsection{Intervention}

Those randomized to the enhanced SOC arm received the SOC message reminding clients to come to a clinic for HIV testing (described above in section 2.3.1), sent three times, a week apart, first in Kiswahili, then in English and then again in Kiswahili.

The intervention consisted of a text message informing participants that HIV self-test kits were available at all North Star Alliance clinics in Kenya. The message was sent three times, a week apart, first in Kiswahili, then in English and then again in Kiswahili, and read: "You can now self-test at home or in the clinic for HIV using a new test kit available from all North Star Alliance clinics in Kenya. Your health, our priority."

\subsubsection{HIV self-testing choice}

Those in the intervention arm who came to a North Star Alliance clinic in Kenya were given a brief demonstration of the self-testing kit and then offered a choice of (1) the standard provider-administered blood-based HIV test; (2) the self-administered oral HIV test for use in the clinic with provider supervision; or (3) a self-administered oral HIV test kit for home use. The client's study arm was identified by the clinic receptionist by looking up the client's cell phone number on an Excel spreadsheet listing the numbers of those in the intervention group. The counselor was informed when an intervention client came in so s/he would be given a demonstration of the self-test kit and then offered the testing choices. 
Those in the intervention arm who visited a North Star Alliance clinic outside Kenya would be offered the SOC test only as those clinics did not have self-test kits. In addition, if someone not in the intervention arm came to a Kenyan clinic and specifically requested a self-testing kit, presumably having heard about them from someone in the intervention group, they were given the self-test so as not to lose an HIV testing opportunity. The HIV testing procedures were as below.

Those who accepted the standard provider-administered blood-based test underwent the standard pre- and post-testing counseling and testing process.

Those who chose the self-test for supervised use in the clinic were given the OraQuick HIV self-test kit (OraSure Technologies 2017) with written (English and Kiswahili) and pictorial instructions in a private room. An HIV Testing and Counseling (HTC) counselor sat in the room with the study participant while s/he used the HIV test (supervised selfadministration) in order to answer any questions that arose during the test administration and offer correction if needed. Upon the availability of the HIV test results 20 minutes later, the client was given the option to view the results in private or with the counselor. After viewing the HIV test results, the client received the standard post-test counseling and any needed referrals. If the client chose to view the test results in private, s/he was encouraged to disclose the test results during post-test counseling, but the final decision whether or not to disclose was the client's. If s/he did not disclose the results, the counselor was to give the post-test counseling information for both scenarios (if the HIV test was positive and if it was negative), including information about accessing HIV care should the test have been positive.

Those who chose to take a test kit for use outside the clinic were given pre-test counseling in the clinic and then instructed to use their test within three days of picking it up and to call or send a text message after using the test to receive a call-back for posttest counseling and any necessary referrals. Participants who failed to contact the clinic staff within three days after obtaining a test kit were called to inquire about the use of the test and provide counseling and referrals if needed. Clients were also told that they could call or send a text at any time while self-testing should they have any questions or concerns. As with in-clinic self-testing, clients were encouraged to disclose their test results during post-test counseling, but whether or not they did so was the client's choice and if $\mathrm{s} /$ he did not disclose the results, the counselor was to provide the information for both HIV test outcome scenarios.

\subsubsection{Follow-up}

Both samples were followed for two months after being sent text messages to assess whether they accessed HIV testing services within that timeframe. A two-month follow-up period was used based on historical data suggesting that reminder messages provide an increase in testing for approximately two weeks, after which testing volume returns to normal. Two months allows for two weeks after the last message is sent plus a few more weeks to capture a few remaining that might trickle in later.

\subsection{Implementation challenges}

For this study, we relied on the electronic medical record system used by the North Star Alliance clinic system for data on study participants and outcomes. Medical record data are notorious for being messy (Kopytoff 2014). The system is dynamic and changes over 
time as patient information is updated. Entry of data into the system at each clinic may have a time lag; some data may be entered incorrectly, entered into the wrong field or file, or never entered at all. What this means is that someone who met eligibility criteria at one point in time may have data added to the system at a later date that indicates s/he is ineligible. Outcome data may not be entirely accurate at the time they were pulled from the system if some data entry were pending; and phone numbers, which were used for the consent and intervention and also reconfigured to create unique ID numbers for merging data in this study, might be updated over the course of the study, making it impossible to link baseline data with outcome data for some participants.

However, the large sample size available through the use of medical record data may provide sufficient power to overcome some of this messiness. In addition, the data errors are unlikely to be differential by study arm, especially in an RCT, and so we would expect that the direction of the bias due to data misclassification should be toward the null, making interpretation of the results easier.

As described later in this report, we found that some participants for whom we had administrative data from the clinic indicating that they had tested for HIV (our outcome of interest) did not have this indication in the electronic medical record system. While we were able to clean the data based on the clinic records, that cleaning could only be done for those in the intervention group, for whom such records were available, and thus would lead to differential misclassification, with greater error rates in the SOC groups than in the intervention group. Therefore, for our primary analysis we used the electronic medical record data without correction, but we also ran the analysis with the corrections we were able to make to compare the impact under the two analytic methods.

\section{Data and methods}

For this study (registered at RIDIE-STUDY-ID-582a2462ae2ab), we took advantage of the electronic record system and selected two separate samples of clients, one of male truckers and one of FSWs registered in the North Star Alliance electronic medical record system.

\subsection{Sample, eligibility criteria and consent}

Eligibility criteria for each sample were: (1) No indication that they were HIV-positive; (2) resident in Kenya; (3) had a valid cell phone number listed; (4) had fewer than 4 HIV tests in the past 12 months (indicating that they were not following the recommendation to test every 3 months for 4 tests per year); (5) had not had an HIV test in the past 3 months; (6) had not participated in our previous study on self-administered HIV testing (Kelvin et al. 2017a; b); and (7) had an indication of male sex and trucker (driver or assistant) or female sex and sex worker.

Once the sample of eligible participants was selected from the electronic record system, we cleaned the data to remove duplicate entries with the same phone number so we would not send them study-related text messages multiple times. We kept the entry with the most recent HIV test date for the sample. The North Star Alliance then sent the following passive consent text message twice, once in Kiswahili and once in English, a week apart: 
North Star Alliance is evaluating our programs for their improvement using client information from our system. The information we use for this evaluation will not be linked to your name and you will not be contacted or have any expenses related to your inclusion. If you have questions about the use of your data, call [phone number of clinic where they had last been seen]. To have your data excluded, reply "NO" to this text.

After each consent message, any clients who contacted us indicating they wanted to opt out of having their data included were removed from the sample prior to randomization. Any further requests to opt out after randomization were considered study drop-outs and their data excluded from analysis.

\subsection{Randomization}

We conducted the study first with the trucker sample, which was randomized on 20 December 2016, and then randomized the FSW sample on 2 March 2017 a few months later so as not to overwhelm the clinics with the new procedures. The eligible individuals in our samples who did not communicate their desire to opt out of the evaluation were randomized in a 1:1:1 ratio to one of the three study arms.

\subsection{Sample size and power}

Our primary outcome of interest was the comparison of HIV testing rates over a twomonth period following the first text message between the intervention and enhanced SOC arms. Current HIV testing rates among clients who have not tested in the past three months at the North Star Alliance clinics in Kenya is $50-58 \%$ for truck drivers and 38 $48 \%$ among sex workers, depending on the month. We calculated sample size assuming the enhanced SOC would achieve the current highest rate (i.e. $58 \%$ among truck drivers and $48 \%$ among sex workers) and found that in order to find a $20 \%$ increase in the probability of testing in the intervention arm compared with the enhanced SOC arm (risk ratio $=1.2$, odds ratio $=1.4$ ) at $80 \%$ power and $95 \%$ confidence level, we would need a sample size of $1,100-1,500$ truck drivers and a similar number of FSWs.

Therefore, we set our target sample size to 750 truck drivers and $750 \mathrm{FSWs}$ in each of the two study arms of primary interest, the intervention and enhanced SOC. All remaining eligible clients were allocated to the SOC arm. Thus, the probability of being randomized into each of the 3 arms was determined by the number of eligible participants in order to ensure 750 in the intervention and 750 in the enhanced SOC arms.

\subsection{Data collection methods}

For this study, we relied on data from two sources: (1) The North Star Alliance electronic medical record system, which documented HIV testing and which test was used (provider-administered test or self-test); and (2) administrative data collected at the clinics in a password-protected Excel spreadsheet for tracking the number of self-test kits used to order resupplies when needed and for documenting that post-test counseling was provided to at-home self-testers. 
The study procedures were approved by the City University of New York Institutional Review Board, the Kenya Medical Research Institute Ethics Committee and the University of KwaZulu-Natal Biomedical Research Ethics Committee.

\subsection{Data analysis}

We described each sample in terms of the basic demographic characteristics (those available in the medical record system) overall and by study arm, and assessed the statistical significance of any differences by study arm using a Chi-Square test for categorical variables and a Kruskal Wallis test for numeric variables. We then conducted logistic regression analysis to compare HIV testing during the two-month follow-up period among clients in the intervention arm versus those in the enhanced SOC arm (primary comparison), as well as among those in the enhanced SOC versus those in the SOC (secondary comparison) to look at the impact of the content of the text message (i.e. about self-test kits or about HIV testing in general) and of the number of text messages (one versus three) on HIV testing, respectively.

We also used logistic regression to look at differences in clinic contact for any reason (e.g. for HIV testing or some other reason) between the groups to see if the text message brought more clients to the clinic even if some then chose not to test.

Finally, we looked at whether the differences by study arm in HIV testing were modified by HIV testing history (whether the client had an HIV test at a North Star Alliance clinic in the past year or not) and, for those in the intervention arm, we describe the HIV testing choices made.

We found some discrepancies between the electronic medical record data and the clinic administrative records that were kept on self-testers for a number of people who selftested for HIV in the intervention group. Specifically, there were 5 truckers and 38 sex workers whose data in the electronic medical record system did not indicate an HIV test, but the clinics had listed them as having self-tested. This might happen for a number of reasons, such as the counselor forgetting to enter the data in the online system, or entering the data but the internet connection being cut while they were being sent to the server, or the data having been entered after we took our data download for these analyses. The data were downloaded from the medical record system five months after follow-up had ended for the truckers and two months after completing follow-up for the FSWs, which might explain the larger number of sex workers missing an HIV test indication in the system if some data were entered after a significant time lag.

Because of this discrepancy, we analyzed the data first including these 5 truckers and 38 sex workers as not having tested (as indicated in the electronic medical records), because we did not have similar administrative data on HIV testing from the clinics for those in the SOC arms.

Differential data cleaning could bias the results and incorrectly elevate the association between the intervention and HIV testing. We felt it best to err on the conservative side, knowing that we might have bias toward the null. However, we also ran the analysis coding those 5 truckers and 38 sex workers as having tested, as indicated in the administrative clinic records, to see if it changed our results substantively. While the 
strength of the effect increased, as would be expected, the conclusions regarding the significance of the associations remained unchanged in all comparisons.

\subsection{Cost-effectiveness analysis}

\subsubsection{Costing perspective and approach}

Costs were estimated from the provider perspective using 2016 prices. Costs incurred prior to this period were adjusted for inflation using the annual average Kenyan inflation rate of $5.53 \%$ and $7.78 \%$ for 2015 and 2016 , respectively (UNAIDS 2000; Kenya National Bureau of Statistics (KNBS) 2016). Costs were estimated in Kenyan shillings (KES). In cases where costs were obtained in other international currencies, they were converted into the local currency. Once the analysis was complete, the results were converted to US dollars (USD) for international comparative purposes. The study used an average annual exchange rate for the base year (2016) of $101.51 \mathrm{KES} / 1.00 \mathrm{USD}$ (UNAIDS 2000). The unit of analysis identified by this study is the HTC client; hence, this costing analysis quantified the cost per client tested.

A mixed-methods approach was used to identify, measure and value costs (Hendriks et al. 2014). Costs were identified and valued using a bottom-up micro-costing approach where data were available, with the remainder estimated using a top-down gross-costing approach (Hendriks et al. 2014). Resources were allocated in line with an activity-based approach (Creese and Parker 1994; UNAIDS 2000), according to their economic classification, per the activities identified:
a. sending text messages
b. pre-counseling
c. HIV testing
d. post-test counseling
e. call-back counseling.

A secondary classification between direct and indirect costs was then implemented (Hendriks et al. 2014). In the context of this study, direct costs arose solely from the provision of the HTC service and were allocated as such. Direct costs emanating from this study included staff directly involved in $\mathrm{HTC}$, as well as consumables used during the HTC process. All costs related to the text message service were also considered to be directly linked to that particular activity. All indirect costs identified (those not specifically borne by the HTC service) were allocated proportionally based on the amount of time healthcare providers spent per activity, such as buildings and overhead costs. All resources identified to have a lifespan greater than a year were treated as capital items and costed as such (UNAIDS 2000). In addition to infrastructure and equipment, this included non-recurrent training and recruitment costs.

\subsubsection{Data collection and analysis}

The cost of providing HIV testing to clients within the different study arms depended on a number of key economic inputs including staff, consumables and medical supplies, equipment and infrastructure, training, and facility management and supervision. The approach to the collection and analysis of the data are described in the following sections:

- Measurement and valuation of cost items

- Cost allocation 
- Cost-effectiveness analysis

- Outcomes

- Uncertainty analysis.

Measurement and valuation of cost items

Per-client costs were estimated by activity for each resource identified. Primary cost data were collected. For certain resources, unit costs were available at client level, which were multiplied by the patient utilization of the resource to obtain a cost-per-client estimate (Hendriks et al. 2014). In the absence of client-level data, average monthly costs per clinic were divided by the average number of HTC clients per month utilizing the clinic, in order to arrive at a cost-per-client estimate (Hendriks et al. 2014).

Patient utilization data were collected using questionnaires designed, first, to identify the exhaustive list of resources used within each of the activities; and second, to estimate the patient utilization of each resource - the cost identification process for each activity (Hendriks et al. 2014; UNAIDS 2000).

The questionnaire in Table 1 was distributed to clinic staff involved with HTC-related functions, as well as relevant head office staff who were directly involved with the RCT, in order to determine the volumes of patient utilization. All data were verified by interviews and discussions held with the relevant staff member or facility manager. The questionnaires became more specific and detailed with each round of data collection until the integrity and level of detail of the patient utilization data were satisfactory. Additional information was obtained via email from the clinic and head office staff to clarify any remaining data uncertainties.

Table 1: Patient utilization questionnaire

\begin{tabular}{|l|l|}
\hline Resource & Data requirement \\
\hline Staff & $\begin{array}{l}\text { To obtain patient utilization of staff: } \\
\text { 1) If directly with patient, how many minutes per patient? } \\
\text { 2) If indirectly with patients, what percentage of day spent on activity? }\end{array}$ \\
\hline Equipment & $\begin{array}{l}\text { To obtain patient utilization of equipment: } \\
\text { 1) For total, for all activities that use this equipment, how many patients use it in } \\
\text { a day? } \\
\text { 2) For specific, for activity only, how many patients use it in a day? } \\
\text { 3) What percentage of equipment is dedicated to activity per day? }\end{array}$ \\
\hline $\begin{array}{l}\text { Consumables } \\
\text { costs }\end{array}$ & $\begin{array}{l}\text { To obtain patient utilization: } \\
\text { 1) For consumables, how many of each item are used per patient? }\end{array}$ \\
\hline 2) For $\underline{\text { running costs, how many patients benefit from this per month? }}$
\end{tabular}


To value each resource used, multiple interviews and discussions were held with relevant head office staff involved with the RCT, as well as facility managers, to obtain the necessary cost information outlined in Table 2 (Hendriks et al. 2014; UNAIDS 2000). As with the patient utilization data collection process, the questionnaires became more specific and detailed with each round of data collection until the integrity and detail of unit cost data were satisfactory.

Table 2: Unit cost questionnaire

\begin{tabular}{|l|l|}
\hline Resource & Data requirement \\
\hline Staff & $\begin{array}{l}\text { 1) What are their salary \& benefits? } \\
\text { 2) How many days do they work per year? }\end{array}$ \\
\hline Equipment & $\begin{array}{l}\text { 1) What was the cost of this equipment? } \\
\text { 2) How many years will this equipment last before it needs to be replaced? } \\
\text { 3) What is the cost to maintain this equipment per month? }\end{array}$ \\
\hline $\begin{array}{l}\text { Consumables } \\
\text { \& running costs }\end{array}$ & $\begin{array}{l}\text { 1) What is the cost of each consumable? } \\
\text { 2) What are the running costs to provide this service per month? }\end{array}$ \\
\hline Infrastructure & $\begin{array}{l}\text { 1) What was the cost of the facility? } \\
\text { 2) How long will this facility last before it needs to be replaced? } \\
\text { 3) What does it cost to maintain the facility? }\end{array}$ \\
\hline Overheads & $\begin{array}{l}\text { 1) What do all of the indirect cost items cost per month? } \\
\text { 2) Overall, how many patients attend the facility per month? }\end{array}$ \\
\hline
\end{tabular}

Additional information was obtained via email from the clinic and head office staff. Where costs and costing information could not be ascertained, assumptions were made and rationalized.

Capital costs incurred by all three study arms, such as infrastructure, furniture and equipment, were annuitized and apportioned for the HTC's share of usage (Hendriks et al. 2014; UNAIDS 2000). The annuity calculation was performed in Microsoft Excel 2016 using the PMT function and required inputs such as interest rate, lifespan of the item, and purchase price. These inputs were converted to monthly values in order to estimate the monthly replacement value for each of the capital items. This study used an interest rate of 10.67 per cent, the average 2016 Central Bank interest rate for Kenya (KNBS 2016), in line with the costing guide (Hendriks et al. 2014). Where possible, estimates of useful life were used that were specific to the resource (Hendriks et al. 2014; UNAIDS 2000), instead of annuitizing all capital inputs over a general three-to-five-year period like other costing studies (Grabbe et al. 2010; Maheswaran et al. 2016; Sweat et al. 2000). This was considered to be a more contextually relevant approach.

\section{Cost allocation}

Indirect costs and those shared across multiple North Star healthcare services were allocated to the HTC function according to the proportion of HTC clients treated by the facility, which was estimated at 44.41 per cent (Grabbe et al. 2010; Hendriks et al. 2014; Maheswaran et al. 2016). This was verified by the facility managers, who estimated that the HTC function accounts for almost half of the clinic's resources and staff time.

The counselors reported spending 30 minutes per client on average for HTC. More specifically, for the average HTC client (in the SOC or enhanced SOC arms), the 30minute period was utilized as follows: 5 minutes spent on pre-test counseling, 20 minutes 
conducting the HIV test and 5 minutes on post-test counseling. Thus, the HTC share of indirect or shared costs was apportioned accordingly to each activity within the HTC function (Creese and Parker 1994): Activities B (5/30), C (20/30) and D (5/30), based on the fraction of time spent by the counselors on each activity (Hendriks et al. 2014).

For the HIV self-test function (offered to participants in the intervention arm), the cost allocation followed the same rationale used for $\mathrm{HTC}$, but with different proportions. The HTC counselors were trained to provide a five-minute demonstration of how to use the self-testing kit for clients who required guidance. Thus, for those who self-tested in the clinic with provider supervision, the total time spent by the counselor was 35 minutes: Activities B (5/35); C (25/35), which included the self-test demonstration; and D (5/35). For those who self-tested at home, the total time was 15 minutes, but the activities comprising home-based HIV self-testing were still costed out of 35 minutes for methodological consistency: Activities B (5/35) for the pre-test counseling; $C(5 / 35)$ for the self-test demonstration; and E (5/35) for the call-back counseling (Hendriks et al. 2014).

\section{Cost-effectiveness analysis}

This study took an incremental approach to analyzing the costs and effects of the RCT programs, using incremental cost-effectiveness ratios (ICERs) (Drummond et al. 2015).

ICER $=(C 1-C 0) /(E 1-E 0)$,

where $(\mathrm{C} 1-\mathrm{C} 0)$ is the magnitude of the increase in the cost of moving from one intervention to another and $(E 1-E 0)$ is the magnitude of the increase in outcomes resulting from that change in intervention.

C0: Cost per client tested associated with the existing intervention

C1: Cost per client tested associated with the intervention under analysis

E0: The number of clients tested as a result of the existing intervention

E1: The number of clients tested as a result of the intervention under analysis

The above equation was used to calculate the incremental cost of moving from the SOC to the enhanced SOC arm (ICERESOC) and, similarly, to calculate the incremental cost of moving from the enhanced SOC to the intervention (ICERINT). More specifically, the difference in cost between the enhanced SOC and the SOC was divided by the associated change in outcome between the two study arms, in order to calculate the ICERESOC. Similarly, the difference in cost of moving from the enhanced SOC to the intervention was divided by the associated change in outcome between the two study arms, to calculate ICERINT (Drummond et al. 2015).

The study arms were then ranked according to their respective ICERs into a league table. The study arm associated with the lowest cost per unit of effect was deemed to be the most cost-effective (Drummond et al. 2015). In general, the lower the ICER, the more cost-effective the intervention. A negative ICER could either mean that the new intervention is less effective and more costly than the existing intervention, or, that the new intervention is more effective and less costly than the existing intervention (Drummond et al. 2015). 


\section{Outcomes}

The HIV testing outcome data for each of the three study arms in the RCT based solely on the data in the electronic medical record (i.e. excluding those additional 5 truckers and 38 FSWs who had an indication of self-testing in the clinic administrative records but not in the electronic medical record system) were used in our analysis.

The percentage of male truck drivers who tested was low across the RCT, with $3.47 \%$ testing in the intervention arm; and $1.34 \%$ and $1.31 \%$ testing in the enhanced SOC and SOC arms, respectively. Of the 26 male truck drivers in the intervention arm that tested, $15(57.7 \%)$ opted for a self-test, with 6 opting for the provider-administered blood HIV test in the clinic. The percentage of FSWs who tested during the RCT was higher, with $10.80 \%$ testing in the intervention arm; and $6.13 \%$ and $6.17 \%$ testing in the enhanced SOC and SOC arms, respectively. Of the $81 \mathrm{FSWs}$ in the intervention arm that tested, 33 $(40.7 \%)$ opted for a self-test, with the remaining 48 opting for the provider-administered HIV test.

\section{Uncertainty analysis}

The study addressed uncertainty by performing a series of univariate sensitivity analyses on the major cost drivers and key parameters identified. This determined the robustness of the cost analysis; and the impact on the resulting average cost per client and the ICERs estimated.

Finally, a scenario analysis was conducted that estimated optimal response rates for the SMS and HIV self-test interventions, and a cost for HIV self-test kits of USD 3.00 (a figure likely to be closer to the actual cost that kits will be procured at in Kenya).

\section{Results}

\subsection{Trucker sample results}

\subsubsection{Description of the sample}

On 13 December 2016, we selected the sample of 4,132 trucker clients from the medical record system who met the eligibility criteria. We deleted duplicate phone numbers from the sample, leaving only the case of the phone number with the most recent HIV test date. These duplicates were cases in which the same phone number was associated with different client names in the system, likely because the client was registered multiple times in the system due to the entry of variations in name either on purpose by the client (i.e. he did not want a particular clinic visit to be associated with his real name) or due to data entry errors. This left us with a sample of 2,324 truckers with unique phone numbers to whom we sent the first consent text message, after which 6 truckers contacted us to opt out; and a week later we sent the second consent text message, after which an additional 21 truckers contacted us to opt out. We also excluded 35 due to invalid phone numbers.

On 20 December 2016 we randomized the remaining 2,262 truckers to the intervention arm $(n=750)$, enhanced SOC arm $(n=750)$ or SOC arm $(n=762)$ and sent the first text message according to their study arm. The text messages were sent two more times, a week apart, for those in the intervention and enhanced SOC arms. During the follow-up period, two additional truckers contacted us to opt out and were excluded from analysis as study drop-outs (Figure 1). 
Figure 1: Flow of male truck driver participants (Consort Flowchart)

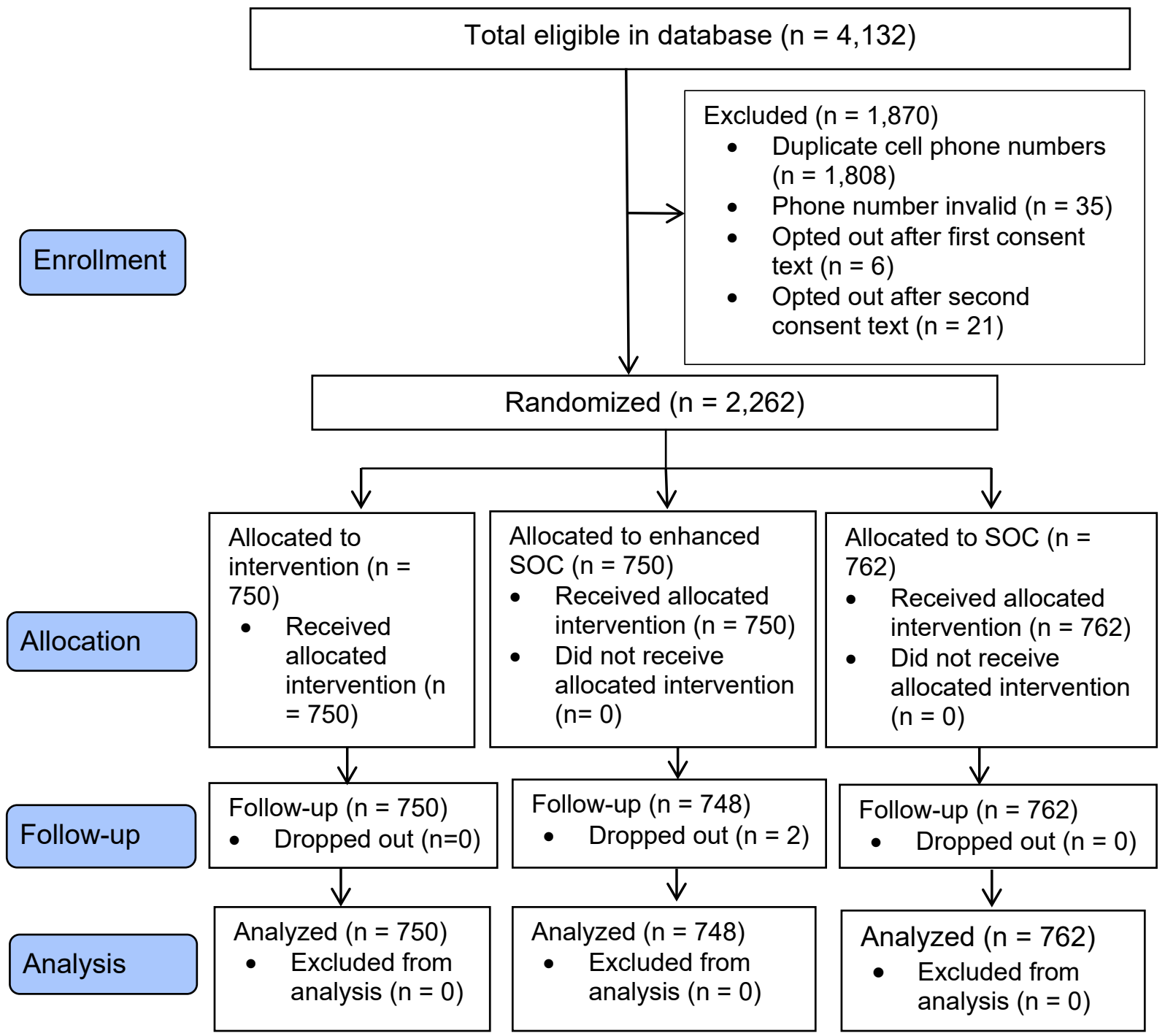

The mean age of the remaining truckers included in the final sample was 35.3 years and the majority $(76.3 \%)$ were married or living with a partner. Most truckers worked as drivers (84.9\%) and only 15.1 per cent were trucking assistants. Overall, 73.1 per cent had not had an HIV test in the past year, and among those who had tested in the past year, the mean time since testing was 5.9 months. The percentage of participants in the sample varied by clinic in which they last received services, from 0.2 per cent in Maai Mahui to 27.7 per cent in Salgaa. Three truckers had last received services in clinics outside Kenya (one in Tanzania and two in Uganda). There were no significant differences in these characteristics by study arm (Table 3). We also compared the characteristics of those in the intervention arm with only those in the enhanced SOC arm (excluding those in the traditional SOC arm), as this was our primary comparison of interest, and found no significant differences (data not shown). 
Table 3: Descriptive statistics for the sample overall and by the three study arms

\begin{tabular}{|c|c|c|c|c|c|}
\hline & Total & Intervention & Enhanced SOC & SOC & p-value \\
\hline Total, n (\%) & $2,260(100.0 \%)$ & $750(33.2 \%)$ & $748(33.1 \%)$ & $762(33.7 \%)$ & NA \\
\hline Male, n (\%) & $2,260(100.0 \%)$ & $750(33.2 \%)$ & $748(33.1 \%)$ & $762(33.7 \%)$ & NA \\
\hline Age & & & & & $0.590^{1}$ \\
\hline Mean (SD) & $35.3(8.7)$ & $35.2(8.9)$ & $35.5(8.6)$ & $35.2(8.5)$ & \\
\hline Median (Range) & $34.0(18.0-76.0)$ & $34.0(18.0-75.0)$ & $34.5(18.0-76.0)$ & $34.0(18.0-68.0)$ & \\
\hline Marital status, n (\%) & & & & & 0.561 \\
\hline Married/Cohabitating & $1,725(76.3 \%)$ & $569(75.9 \%)$ & $581(77.7 \%)$ & $575(75.5 \%)$ & \\
\hline Unmarried (single, divorced/separated) & $535(23.7 \%)$ & $181(24.1 \%)$ & $167(22.3 \%)$ & $187(24.5 \%)$ & \\
\hline Trucker job, n (\%) & & & & & 0.859 \\
\hline Driver & $1,917(84.9 \%)$ & $633(84.4 \%)$ & $634(84.9 \%)$ & $650(85.4 \%)$ & \\
\hline Assistant (turnboy) & $341(15.1 \%)$ & $117(15.6 \%)$ & $113(15.1 \%)$ & $111(14.6 \%)$ & \\
\hline Missing & 2 & 0 & 1 & 1 & \\
\hline Test in past year, $\mathrm{n}(\%)$ & & & & & 0.254 \\
\hline Yes & $607(26.9 \%)$ & $199(26.5 \%)$ & $188(25.1 \%)$ & $220(28.9 \%)$ & \\
\hline No & $1,653(73.1 \%)$ & $551(73.5 \%)$ & $560(74.9 \%)$ & $542(71.1 \%)$ & \\
\hline $\begin{array}{l}\text { Months since last test among those tested in past year } \\
\text { (among those who tested in past year) }\end{array}$ & & & & & 0.301 \\
\hline Mean (SD) & $5.9(2.6)$ & $5.8(2.5)$ & $6.1(2.7)$ & $5.8(2.6)$ & \\
\hline Median (Range) & $4.0(3.0-11.0)$ & $4.0(3.0-11.0)$ & $5.0(3.0-11.0)$ & $4.0(3.0-11.0)$ & \\
\hline North Star Alliance Clinic where last seen, n (\%) & & & & & $0.582^{2}$ \\
\hline Burnt Forest, Kenya & $17(0.8 \%)$ & $7(0.9 \%)$ & $5(0.7 \%)$ & $5(0.8 \%)$ & \\
\hline Emali, Kenya & $176(7.8 \%)$ & $53(7.1 \%)$ & $57(7.6 \%)$ & $66(8.7 \%)$ & \\
\hline Jomvu, Kenya & $1,094(48.4 \%)$ & $363(48.4 \%)$ & $370(49.5 \%)$ & $361(47.4 \%)$ & \\
\hline Maai Mahiu, Kenya & $5(0.2 \%)$ & $3(0.4 \%)$ & $1(0.1 \%)$ & $1(0.1 \%)$ & \\
\hline Mlolongo, Kenya & $20(0.9 \%)$ & $4(0.5 \%)$ & $9(1.2 \%)$ & $7(0.9 \%)$ & \\
\hline Mombasa, Kenya & $146(6.5 \%)$ & $45(6.0 \%)$ & $57(7.6 \%)$ & $44(5.8 \%)$ & \\
\hline Namanga, Kenya & $174(7.7 \%)$ & $54(7.2 \%)$ & $51(6.8 \%)$ & $69(9.1 \%)$ & \\
\hline Salgaa, Kenya & $625(27.7 \%)$ & $220(29.3 \%)$ & $197(26.3 \%)$ & $208(27.3 \%)$ & \\
\hline Malaba, Uganda & $1(0.0 \%)$ & $0(0.0 \%)$ & $0(0.0 \%)$ & $1(0.1 \%)$ & \\
\hline Katuna, Uganda & $1(0.0 \%)$ & $0(0.0 \%)$ & $1(0.1 \%)$ & $0(0.0 \%)$ & \\
\hline Tunduma, Tanzania & $1(0.0 \%)$ & $1(0.1 \%)$ & $0(0.0 \%)$ & $0(0.0 \%)$ & \\
\hline
\end{tabular}

${ }^{1} \mathrm{p}$-value from Kruskal Wallis test

${ }^{2} p$-value from Chi-square test 


\subsubsection{Logistic regression models comparing those in the intervention arm to those in the enhanced SOC arm}

Overall $10(1.3 \%)$ truckers in the enhanced SOC group and $26(3.5 \%)$ in the intervention group tested for HIV during the 2-month follow-up. Those in the intervention group had 2.7 times greater odds of HIV testing compared with those in the enhanced SOC group, which was statistically significant $(p=0.009)$. If we include the additional 5 truckers who had an indication of HIV self-testing in the administrative clinic records as having tested, the odds ratio increases to $3.2(p=0.002)$ (Table 4$)$. The difference by study arm in HIV testing was not modified by having tested in the past year (interaction p-value $=0.669$ ) (data not shown).

Table 4: Logistic regression model results for HIV testing and clinic contact comparing the intervention with the enhanced SOC arms

\begin{tabular}{|c|c|c|c|c|c|}
\hline & Total, $\mathbf{n}(\%)$ & $\begin{array}{l}\text { Enhanced SOC } \\
\text { arm, n (\%) }\end{array}$ & $\begin{array}{l}\text { Intervention } \\
\text { arm, } \mathbf{n}(\%)\end{array}$ & OR $(95 \% \mathrm{Cl})$ & $\begin{array}{l}\text { Chi-Square } \\
\text { p-value }\end{array}$ \\
\hline Total & $1,498(100.0 \%)$ & $748(49.9 \%)$ & $750(50.1 \%)$ & NA & NA \\
\hline \multicolumn{6}{|c|}{ HIV tested (according to electronic medical record system) } \\
\hline Yes & $36(2.4 \%)$ & $10(1.3 \%)$ & $26(3.5 \%)$ & $2.7(1.3-5.5)$ & 0.009 \\
\hline No & $1,462(97.6 \%)$ & $738(98.7 \%)$ & $724(96.5 \%)$ & & \\
\hline \multicolumn{6}{|c|}{$\begin{array}{l}\text { HIV tested (including the } 5 \text { participants with an indication of HIV testing in the clinic records as } \\
\text { having tested) }{ }^{1}\end{array}$} \\
\hline Yes & $41(2.7 \%)$ & $10(1.3 \%)$ & $31(4.1 \%)$ & $3.2(1.6-6.5)$ & 0.002 \\
\hline No & $1,457(97.3 \%)$ & $738(98.7 \%)$ & $719(95.9 \%)$ & & \\
\hline \multicolumn{6}{|c|}{ Received any clinic services (according to electronic medical record system) } \\
\hline Yes & $169(11.3 \%)$ & $80(10.7 \%)$ & $89(11.9 \%)$ & $1.1(0.8-1.6)$ & 0.474 \\
\hline No & $1,329(88.7 \%)$ & $668(89.3 \%)$ & $661(88.1 \%)$ & & \\
\hline \multicolumn{6}{|c|}{$\begin{array}{l}\text { Received any clinic services (including the } 5 \text { participants with an indication of HIV testing in the } \\
\text { clinic records as having received clinic services) }{ }^{1}\end{array}$} \\
\hline Yes & $174(11.6 \%)$ & $80(10.7 \%)$ & $94(12.5 \%)$ & $1.2(0.9-1.6)$ & 0.267 \\
\hline No & $1,324(88.4 \%)$ & 668 (89.3\%) & $656(87.5 \%)$ & & \\
\hline
\end{tabular}

${ }^{1}$ Five clients were noted as having HIV tested in the clinic administrative records used for tracking self-test kits and post-test counseling, but their test was not indicated in the electronic medical record system. Here, these five are recoded (data cleaned based on additional information) as having HIV-tested and the analysis rerun.

In our sample, 169 clients had some form of contact with the North Star Alliance clinics during the follow-up period, $80(10.7 \%)$ in the enhanced SOC arm and $89(11.9 \%)$ in the intervention arm. Those in the intervention arm had 1.1 times greater odds of clinic contact compared with those in the enhanced SOC arm, but the difference was not statistically significant $(p=0.474)$. If we include the additional 5 truckers who had an indication of HIV self-testing in the administrative records as having had clinic contact, the odds ratio increases to $1.2(p=0.267)$ (Table 4).

\subsubsection{Logistic regression models comparing those in the enhanced SOC arm with those in the SOC arm}

Overall, $10(1.3 \%)$ clients in the SOC arm and $10(1.3 \%)$ in the enhanced SOC arm tested for HIV over the 2-month follow-up period ( $O R=1.0, p=0.967)$. There was also no difference in clinic contact between the two groups $(10.6 \%$ in the SOC arm, $10.7 \%$ in the enhanced SOC arm, OR $=1.0, p=0.987$ ) (Table 5). 
Table 5: Logistic regression model results for HIV testing and clinic contact comparing the enhanced SOC with the SOC arms

\begin{tabular}{llllll}
\hline & Total, $\mathbf{n}(\%)$ & SOC arm, $\mathbf{n}(\%)$ & $\begin{array}{l}\text { Enhanced SOC } \\
\text { arm, } \mathbf{n}(\%)\end{array}$ & OR (95\% CI) & $\begin{array}{l}\text { Chi-Square } \\
\text { p-value }\end{array}$ \\
\hline $\begin{array}{l}\text { Total } \\
\text { with }\end{array}$ & $1,510(100.0 \%)$ & $762(50.5 \%)$ & $748(49.5 \%)$ & NA & NA \\
$\begin{array}{l}\text { HIV tested } \\
\text { Yes } \quad 20(1.3 \%)\end{array}$ & $10(1.3 \%)$ & $10(1.3 \%)$ & $1.0(0.4-2.5)$ & 0.967 \\
No $\quad 1,490(98.7 \%)$ & $752(98.7 \%)$ & $738(98.7 \%)$ & & \\
$\begin{array}{l}\text { Received any clinic services } \\
\text { Yes } \quad 161(10.7 \%)\end{array}$ & $81(10.6 \%)$ & $80(10.7 \%)$ & $1.0(0.7-1.4)$ & 0.967 \\
No & $1,349(89.3 \%)$ & $681(89.4 \%)$ & $668(89.3 \%)$ & & \\
\hline
\end{tabular}

\subsubsection{HIV testing choices made among those in the intervention arm}

Of the 31 truckers who tested in the intervention arm (including the 5 identified in the administrative clinic records only), 20 (64.5\%) chose a self-test. Of those, $14(70.0 \%)$ chose to self-test in the clinic with supervision, $5(25.0 \%)$ chose to take a test kit for home use, and $1(5.0 \%)$ initially took a test kit for home use but then changed his mind and returned to the clinic to test with supervision (Table 6).

Table 6: description of HIV testing choices made for those in the intervention arm who tested ${ }^{1}$

\begin{tabular}{|c|c|}
\hline & Study sample \\
\hline Total testers in the intervention group & $31(100.0 \%)$ \\
\hline \multicolumn{2}{|l|}{ Chose a self-test } \\
\hline Yes & $20(64.5 \%)$ \\
\hline No & $11(35.5 \%)$ \\
\hline \multicolumn{2}{|l|}{ Self-testing method chosen among those who self-tested } \\
\hline In the clinic with counselor supervision & $14(70.0 \%)$ \\
\hline Took test kit for home use & $5(25.0 \%)$ \\
\hline $\begin{array}{l}\text { Took test kit for home use but returned to } \\
\text { the clinic to use it with supervision }\end{array}$ & $1(5.0 \%)$ \\
\hline \multicolumn{2}{|l|}{ Contacted clinic during or after self-testing at home } \\
\hline Called while testing with questions & $2(33.3 \%)^{2}$ \\
\hline Called after testing for post-test counseling & $1(16.7 \%)$ \\
\hline Called both during and after testing & $2(33.3 \%)$ \\
\hline Did not call & $1(16.7 \%)$ \\
\hline $\begin{array}{l}\text { Number of contact attempts made by counselor to reach the } \\
\text { client who took self-test kit but did not call }\end{array}$ & 2 \\
\hline
\end{tabular}


Of the 6 who took a test kit for home use (including the one who changed his mind), 3 $(50.0 \%)$ called while testing with questions, including the client who returned to the clinic to test with supervision, and $3(50.0 \%)$ called after testing for post-test counseling (2 called both during the testing and after for counseling). One client did not call the counselor at all and it took two attempts for the counselor to reach him to learn that he had used the test and provide post-test counseling (Table 6). Five participants tested HIV-positive during the study, all of whom were in the intervention group (data not shown).

An additional six clients not in the study asked for a self-test kit during the study. They were given a test kit and followed according to the study protocol to ensure they received appropriate counseling and support (data not shown).

\subsection{Sex worker sample results}

\subsubsection{Description of the sample}

On 13 February 2017, we selected the sample of 2,364 FSW clients from the medical record system who met eligibility criteria. We deleted duplicate phone numbers from the sample, leaving only the one case of the number with the most recent HIV test date. Duplicate numbers were cases in which the same phone number was associated with different client names in the system. This left us with a sample of 2,349 sex workers to whom we sent the first consent text message, after which 116 sex workers contacted us to opt out and 15 phone numbers were returned as invalid; and a week later we sent the second consent text message, after which an additional 22 sex workers contacted us to opt out.

On 2 March 2017, the remaining 2,196 sex workers were randomized to the intervention $(n=750)$, enhanced SOC $(n=750)$ or SOC $(n=696)$ arms and the first study text messages were sent according to their study arm. The text messages were sent two more times, a week apart, for those in the intervention and enhanced SOC arms (Figure 2). 
Figure 2: Flow of female sex worker participants (Consort Flowchart)

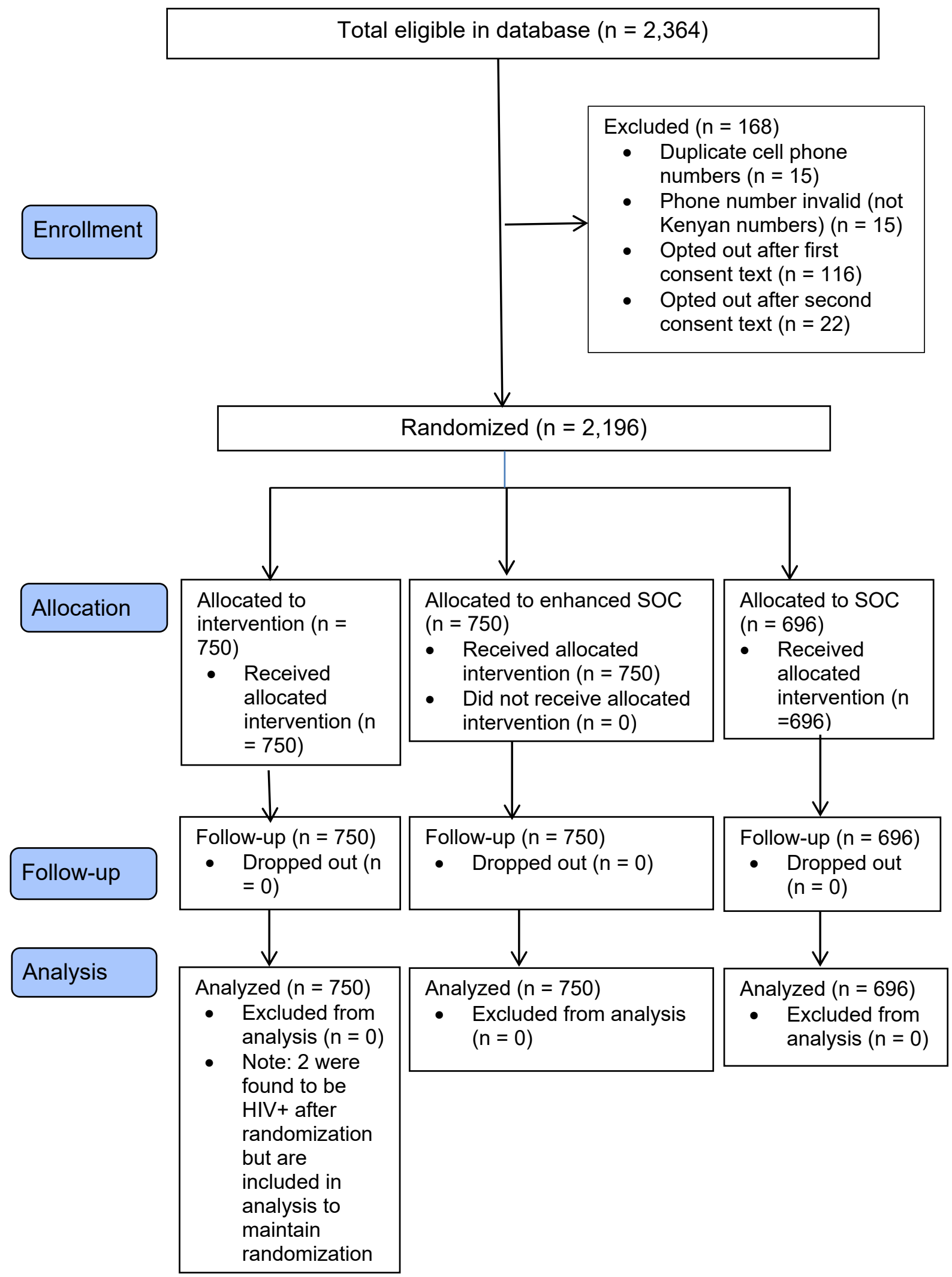


The mean age of the FSWs was 28.6 years and only a few were married or living with a partner (8.8\%). Overall, 64.7 per cent of the sex worker sample had not had an HIV test in the past year. Among those who had tested in the past year, the mean time since testing was 6.3 months. The percentage of participants in the sample varied by clinic in which they last received services, from 2.6 per cent in Burnt Forest to 32.3 per cent in Salgaa. There were no significant differences in these characteristics by study arm (Table 7). We also compared the characteristics of those in the intervention arm to only those in the enhanced SOC arm (excluding those in the traditional SOC arm), as this was our primary comparison of interest, and found no significant differences (data not shown).

Table 7: Descriptive statistics for female sex worker sample overall and by study arm

\begin{tabular}{|c|c|c|c|c|c|}
\hline & Total & Intervention & $\begin{array}{l}\text { Enhanced } \\
\text { sOC }\end{array}$ & SOC & p-value \\
\hline Total, n (\%) & $\begin{array}{l}2,196 \\
(100.0 \%)\end{array}$ & $750(34.2 \%)$ & $750(34.2 \%)$ & $696(31.7 \%)$ & NA \\
\hline Female, n (\%) & $\begin{array}{l}2,196 \\
(100.0 \%)\end{array}$ & $750(34.2 \%)$ & $750(34.2 \%)$ & $697(31.7 \%)$ & NA \\
\hline Age & & & & & $0.408^{1}$ \\
\hline Mean (SD) & $28.6(5.9)$ & $28.3(5.9)$ & $28.7(6.0)$ & $28.6(5.9)$ & \\
\hline Median (Range) & $\begin{array}{l}28.0(18.0- \\
61.0)\end{array}$ & $\begin{array}{l}28.0(18.0- \\
61.0)\end{array}$ & $\begin{array}{l}28.0(18.0- \\
52.0)\end{array}$ & $\begin{array}{l}28.0(18.0- \\
53.0)\end{array}$ & \\
\hline Marital status, n (\%) & & & & & 0.356 \\
\hline Married/Cohabitating & $176(8.8 \%)$ & $69(9.9 \%)$ & $52(7.7 \%)$ & $55(8.8 \%)$ & \\
\hline $\begin{array}{l}\text { Unmarried (single, } \\
\text { divorced/separated) }\end{array}$ & $1,818(91.2 \%)$ & $625(90.1 \%)$ & $620(92.3 \%)$ & $573(91.2 \%)$ & \\
\hline Test in past year, n (\%) & & & & & $0.862^{2}$ \\
\hline Yes & $776(35.3 \%)$ & $270(36.0 \%)$ & $265(35.3 \%)$ & $241(34.6 \%)$ & \\
\hline No & $1,420(64.7 \%)$ & $470(64.0 \%)$ & $485(64.7 \%)$ & $455(65.4 \%)$ & \\
\hline $\begin{array}{l}\text { Months since last test } \\
\text { among those tested in } \\
\text { past year }\end{array}$ & & & & & $0.144^{1}$ \\
\hline Mean (SD) & $6.3(2.6)$ & $6.6(2.6)$ & $6.2(2.6)$ & $6.3(2.6)$ & \\
\hline Median (Range) & $5.5(3.0-12.0)$ & $6.3(3.0-12.0)$ & \begin{tabular}{|l}
$5.5(3.0-$ \\
$12.0)$
\end{tabular} & $\begin{array}{l}5.5(3.0- \\
12.0)\end{array}$ & \\
\hline \multicolumn{2}{|c|}{$\begin{array}{l}\text { North Star Alliance Clinic where last } \\
\text { seen, } n(\%)\end{array}$} & & & & $0.160^{2}$ \\
\hline Burnt Forest, Kenya & $58(2.6 \%)$ & $19(2.5 \%)$ & $22(2.9 \%)$ & $17(2.4 \%)$ & \\
\hline Emali, Kenya & $267(12.2 \%)$ & $90(12.0 \%)$ & $86(11.5 \%)$ & $91(13.1 \%)$ & \\
\hline Jomvu, Kenya & $364(16.6 \%)$ & $121(16.1 \%)$ & $121(16.1 \%)$ & $122(17.5 \%)$ & \\
\hline Maai Mahiu, Kenya & $265(12.1 \%)$ & $79(10.5 \%)$ & $105(14.0 \%)$ & $81(11.6 \%)$ & \\
\hline Mlolongo, Kenya & $245(11.2 \%)$ & $71(9.5 \%)$ & $85(11.3 \%)$ & $89(12.8 \%)$ & \\
\hline Mombasa, Kenya & $103(4.7 \%)$ & $43(5.7 \%)$ & $38(5.1 \%)$ & $38(5.1 \%)$ & \\
\hline Namanga, Kenya & $185(8.4 \%)$ & $63(8.4 \%)$ & $69(9.2 \%)$ & $53(7.6 \%)$ & \\
\hline Salgaa, Kenya & $709(32.3 \%)$ & $264(35.2 \%)$ & $224(29.9 \%)$ & $221(31.8 \%)$ & \\
\hline
\end{tabular}




\subsubsection{Logistic regression models comparing those in the intervention arm with those in the enhanced SOC arm}

Overall, $106(6.1 \%)$ sex workers in the enhanced SOC group and $81(10.8 \%)$ in the intervention group tested for HIV during the 2-month follow-up. Those in the intervention group had 1.9 times greater odds of HIV testing compared to those in the enhanced SOC group, which was statistically significant $(p=0.001)$. If we include the additional 38 sex workers who had an indication of HIV self-testing in the administrative clinic records but not in the electronic medical record system as having HIV tested, the odds ratio increases to $2.9(p<0.001)$ (Table 8). The difference by study arm in HIV testing was not modified by having tested in the past year (interaction $p$-value $=0.851$ ) (data not shown).

Table 8: Looking at differences in HIV testing and in receiving clinic services in general comparing intervention with the enhanced SOC among female sex workers

\begin{tabular}{|c|c|c|c|c|c|}
\hline & Total, n (\%) & $\begin{array}{l}\text { Enhanced SOC } \\
\text { arm, n (\%) }\end{array}$ & $\begin{array}{l}\text { Intervention } \\
\text { arm, n (\%) }\end{array}$ & $\begin{array}{l}\text { OR }(95 \% \\
\mathrm{Cl})\end{array}$ & $\begin{array}{l}\text { Chi-Square } \\
\text { p-value }\end{array}$ \\
\hline Total & $\begin{array}{l}1,500 \\
(100.0 \%)\end{array}$ & $750(50.0 \%)$ & $750(50.0 \%)$ & NA & NA \\
\hline \multicolumn{6}{|c|}{ HIV tested (according to electronic medical record system) ${ }^{*}$} \\
\hline Yes & $127(8.5 \%)$ & $46(6.1 \%)$ & $81(10.8 \%)$ & $1.9(1.3-2.7)$ & 0.001 \\
\hline No & $1,373(91.5 \%)$ & $704(93.9 \%)$ & $669(89.2 \%)$ & & \\
\hline \multicolumn{6}{|c|}{$\begin{array}{l}\text { HIV tested (including the } 38 \text { participants with an indication of HIV testing in the clinic } \\
\text { records as having tested) }\end{array}$} \\
\hline Yes & $165(11.0 \%)$ & $46(6.1 \%)$ & $119(15.9 \%)$ & $2.9(2.0-4.1)$ & $<0.001$ \\
\hline No & $1,335(89.0 \%)$ & $704(93.3 \%)$ & $631(84.1 \%)$ & & \\
\hline \multicolumn{6}{|c|}{ Received any clinic services (according to electronic medical record system) ${ }^{*}$} \\
\hline Yes & $175(11.7 \%)$ & $70(9.3 \%)$ & $105(14.0 \%)$ & $1.6(1.2-2.2)$ & 0.005 \\
\hline No & $1,325(88.3 \%)$ & $680(90.7 \%)$ & $645(86.0 \%)$ & & \\
\hline \multicolumn{6}{|c|}{$\begin{array}{l}\text { Received any clinic services (including the } 38 \text { participants with an indication of HIV } \\
\text { testing in the clinic records as having received clinic services) }\end{array}$} \\
\hline Yes & $199(13.3 \%)$ & $70(9.3 \%)$ & $129(17.2 \%)$ & $2.0(1.5-2.8)$ & $<0.001$ \\
\hline No & $1,301(86.7 \%)$ & $680(90.7 \%)$ & $621(82.8 \%)$ & & \\
\hline
\end{tabular}

${ }^{*} 38$ clients were noted as having HIV tested in the clinic administrative records used for tracking test kits and post-test counseling, but their test was not indicated in the electronic medical record system.

A total of $70(9.3 \%)$ sex workers in the enhanced SOC arm and $105(14.0 \%)$ in the intervention arm had some form of clinic contact or service during the 2-month follow-up. Those in the intervention arm had 1.6 times greater odds of clinic contact compared with those in the enhanced SOC arm, which was statistically significant $(p=0.005)$. If we include the additional 38 sex workers who had an indication of HIV self-testing in the administrative clinic records but not in the electronic medical record system as having had clinic contact, the odds ratio increases to $2.0(p<0.001)$ (Table 8). 


\subsubsection{Logistic regression models comparing those in the enhanced SOC arm with those in the SOC arm}

Overall, $43(6.2 \%)$ clients in the SOC arm compared with $46(6.1 \%)$ in the enhanced SOC arm tested for HIV over the 2-month follow-up period, giving an odds ratio of 1.0 ( $p$ $=0.972)$. There was also no difference in clinic contact between the two groups $(10.1 \%$ in the SOC arm, 9.3\% in the enhanced SOC arm, OR =0.9, p =642) (Table 9).

Table 9: Looking at differences in HIV testing and in receiving clinic services in general, comparing the enhanced SOC with the traditional SOC

\begin{tabular}{|l|l|l|l|l|l|}
\hline & Total, n (\%) & SOC arm, n (\%) & $\begin{array}{l}\text { Enhanced SOC } \\
\text { arm, n (\%) }\end{array}$ & $\begin{array}{l}\text { OR (95\% } \\
\mathbf{C l})\end{array}$ & $\begin{array}{l}\text { Chi-Square } \\
\mathbf{p - v a l u e}\end{array}$ \\
\hline Total & 1,446 & $750(52.0 \%)$ & $696(48.0 \%)$ & NA & NA \\
\hline HIV tested (according to the electronic medical record system) & $\begin{array}{l}1.0(7.0- \\
1.5)\end{array}$ & 0.972 \\
\hline Yes & $89(6.2 \%)$ & $43(6.2 \%)$ & $46(6.1 \%)$ & & \\
\hline No & $1,357(93.8 \%)$ & $653(93.8 \%)$ & $704(93.9 \%)$ & & 0.642 \\
\hline Received any clinic services (according to the electronic medical record system) \\
\hline Yes & $140(9.7 \%)$ & $70(10.1 \%)$ & $70(9.3 \%)$ & $\begin{array}{l}0.9(0.7- \\
1.3)\end{array}$ & \\
\hline No & $1306(90.3 \%)$ & $626(89.9 \%)$ & $680(90.7 \%)$ & & \\
\hline
\end{tabular}

\subsubsection{HIV testing choices made among those in the intervention arm}

Of the 119 sex workers who tested in the intervention arm (including the 38 identified in the administrative clinic records only), 71 (59.7\%) chose a self-test. One participant took 2 HIV self-test kits from 2 different clinics for home use, resulting in a total of 72 test kits used. Of those, $52(72.2 \%)$ were used in the clinic with supervision and $20(27.8 \%)$ taken for home use (Table 10).

Of the 20 test kits used at home, in $5(25.0 \%)$ cases the participant called while testing with questions; in $3(15.0 \%)$ cases they called after testing for post-test counseling; and in $7(35.0 \%)$ cases they called both while testing with questions and after for counseling. Five $(25.0 \%)$ sex workers did not call at all and the counselor had to call them for posttest counseling. It took 1 attempt to reach 3 of these participants who did not call, 2 attempts for 1 participant and 5 attempts for 1 participant (Table 10). Five sex workers tested HIV-positive during the study, all of whom were in the intervention group (data not shown). 
Table 10: Description of self-testing among female sex workers in the intervention group and six not in the sample who requested a self-test

\begin{tabular}{|l|l|}
\hline & Study Sample \\
\hline Total testers in the intervention group & $119(100.0 \%)$ \\
\hline Chose a self-test & \\
\hline Yes & $71(59.2 \%)$ \\
\hline No & $48(40.3 \%)$ \\
\hline Self-testing method ( $=72$ test kits used) & \\
\hline In the clinic with counselor supervision & $52(72.2 \%)$ \\
\hline Took test kit for home use & $20(27.8 \%)^{*}$ \\
\hline $\begin{array}{l}\text { Took test kit for home use but returned to } \\
\text { the clinic to use it with supervision }\end{array}$ & $0(0.0 \%)$ \\
\hline Contacted clinic when self-testing at home & \\
\hline Yes, while testing with questions & $5(25.0 \%)^{*}$ \\
\hline Yes, after testing for post-test counseling & $3(15.0 \%)^{*}$ \\
\hline Yes, both during and after testing & $7(35.0 \%)$ \\
\hline No & $5(25.0 \%)$ \\
\hline $\begin{array}{l}\text { Number of attempts made by counselor to reach client who took } \\
\text { self-test kit but did not call (n }=5)\end{array}$ \\
\hline One & $3(60.0 \%)$ \\
\hline Two & $1(20.0 \%)$ \\
\hline Three & 0 \\
\hline Four & 0 \\
\hline Five & $1(20.0 \%)$ \\
\hline
\end{tabular}

${ }^{*}$ One person took a self-test kit twice from two difference clinics. The first time she called with questions while testing and the second time she called after testing for post-test counseling.

An additional 22 sex workers not in the study asked for a self-test kit during the study. They were given a test kit and followed according to the study protocol to ensure they received appropriate counseling and support (data not shown).

\subsection{Costing results}

\subsubsection{Costs}

The total cost of the trucker sample was 21 per cent higher for the intervention and enhanced SOC arms, at USD 258.07 and USD 257.88, respectively, compared with USD 212.48 for the SOC arm. This is because fewer text messages were sent to participants in the SOC arm than the other two arms. The cost per client tested calculated for the intervention arm was USD 8.32, while the cost per client for the enhanced SOC and SOC arms was substantially higher at USD 25.79 and USD 21.25 respectively.

Although the total cost was highest for the intervention arm, the cost per client tested was significantly lower due to the higher number of clients who tested in that arm. This trend continued for the FSW sample, with the intervention and enhanced SOC arms costing more than the SOC arm, however cost per client tested was lower in the intervention arm, driven primarily by the greater number of sex workers who tested. Table 11 illustrates the SMS-related costs of the trial, costed as Activity A. 
Table 11: Total SMS costs and average SMS cost per client (Activity A)

\begin{tabular}{|c|c|c|c|c|c|c|}
\hline & \multicolumn{3}{|c|}{ Truckers } & \multicolumn{3}{|c|}{ Sex workers } \\
\hline & \multicolumn{3}{|c|}{ Intervention EnhancedSOC } & \multicolumn{3}{|c|}{ InterventionEnhancedSOC } \\
\hline & & soc & & & soc & \\
\hline $\begin{array}{l}\text { Number of text } \\
\text { messages sent }\end{array}$ & 8,406 & 8,400 & 6,921 & 8,384 & 8,384 & 6,831 \\
\hline $\begin{array}{l}\text { Total cost per text } \\
\text { message (USD) }\end{array}$ & 3.12 & 3.12 & 3.12 & 3.13 & 3.13 & 3.13 \\
\hline $\begin{array}{l}\text { Total cost per study arm } \\
\text { (USD) }\end{array}$ & 258.07 & 257.88 & 212.48 & 3258.34 & 258.34 & 210.49 \\
\hline $\begin{array}{l}\text { Number of HTC clients } \\
\text { per arm }\end{array}$ & 26 & 10 & 10 & 81 & 46 & 43 \\
\hline Cost per client (USD) & 9.93 & 25.79 & 21.25 & 3.19 & 5.62 & 4.90 \\
\hline
\end{tabular}

The average cost per client tested attributed to the provider-administered HIV test and HIV self-test is broken down by economic classification in Table 12. The total costs of the counseling and testing component of the interventions were significantly different, depending on whether the client opted to self-test or for the conventional provider clinicbased test.

Table 12: Average cost per HTC and HIV self-test client (activities B, C, D and E)

\begin{tabular}{|l|l|c|c|c|}
\hline & Resource & $\begin{array}{l}\text { HTC cost per } \\
\text { client (USD) }\end{array}$ & \multicolumn{2}{|c|}{$\begin{array}{l}\text { HIV self-test cost per } \\
\text { client (USD) }\end{array}$} \\
\hline & & & \multicolumn{1}{|l}{ In clinic } & Home-based \\
\hline Staff & HTC counselors & 1.15 & 1.35 & 0.58 \\
\hline $\begin{array}{l}\text { Consumables/medical } \\
\text { supplies/running } \\
\text { costs }\end{array}$ & Various & 0.43 & 9.37 & 9.42 \\
\hline Equipment & Cell phones & - & - & 0.62 \\
\hline Infrastructure & Clinic site & 0.83 & 0.83 & 0.36 \\
\hline Training/recruitment & One-off training & 0.03 & 0.03 & 0.01 \\
\cline { 2 - 5 } & One-off recruitment & 0.00 & 0.00 & 0.00 \\
\hline $\begin{array}{l}\text { Overheads and } \\
\text { supervision }\end{array}$ & Site co-ordinator & 0.51 & 0.51 & 0.22 \\
\cline { 2 - 5 } & General overheads & 2.05 & 2.05 & 0.88 \\
\hline $\begin{array}{l}\text { Total: HIV self-test } \\
\text { cost per client }\end{array}$ & & 5.01 & 14.13 & 12.08 \\
\hline
\end{tabular}

A further difference in cost was dependent on whether the client chose the in-clinic selftesting option, or the home-based self-testing option. The cost per provider-administered HIV test was calculated at USD 5.01, while for HIV self-test, this cost was more than double, at USD 14.13 and USD 12.08 for the two self-testing options. This was mostly driven by the cost of the test kit itself (USD $7.95+16 \%$ VAT), included in Table 12 under consumables/medical supplies/running costs.

For conventional HTC, the bulk of the cost was attributed to staff costs (USD 1.15) and general clinic overheads (USD 2.05). For HIV self-testing, all costs other than the consumables/medical supplies/running costs and staff costs were lower than those calculated for HTC, with the vast majority of the total cost driven by the cost of the test kits. 
Table 13 illustrates the total cost of the HIV testing activities, amounting to USD 1,129.07 for the truckers and USD 2,194.81 for the FSWs. The cost for the FSWs was almost double that of the truck drivers due to the larger number of FSWs who returned for testing. However, the cost per FSW client tested was substantially lower than for the truckers across all study arms. The cost per client tested for the truckers ranged between USD 21.48 and USD 30.80 and from USD 9.90 to USD 15.80 for the FSWs, with the lowest cost per client tested for each group attributed to the intervention, followed by the SOC arm, with the enhanced SOC having the highest cost per client tested.

Table 13: Total cost and cost per client by study arm, truck drivers (Activities AE)

\begin{tabular}{|c|c|c|c|c|c|c|c|c|}
\hline & \multirow{2}{*}{$\begin{array}{l}\text { Number } \\
\text { of HTC } \\
\text { clients }\end{array}$} & \multicolumn{5}{|c|}{ Total cost per activity (USD) } & \multirow{2}{*}{$\begin{array}{l}\text { Total cost } \\
\text { per study } \\
\text { arm (USD) }\end{array}$} & \multirow{2}{*}{$\begin{array}{l}\text { Cost } \\
\text { per } \\
\text { client } \\
\text { (USD) }\end{array}$} \\
\hline & & $\begin{array}{l}\text { Activity } \\
\text { A }\end{array}$ & $\begin{array}{l}\text { Activity } \\
\text { B }\end{array}$ & $\begin{array}{l}\text { Activity } \\
\text { C }\end{array}$ & $\begin{array}{l}\text { Activity } \\
\text { D }\end{array}$ & \begin{tabular}{|l} 
Activity \\
E
\end{tabular} & & \\
\hline \multicolumn{9}{|l|}{ Truckers } \\
\hline Intervention & & 258.06 & 18.20 & 259.14 & 14.11 & 9.00 & 558.51 & 21.48 \\
\hline $\begin{array}{l}\text { Enhanced } \\
\text { SOC }\end{array}$ & 10 & 257.88 & 7.63 & 34.84 & 7.63 & - & 307.98 & 30.80 \\
\hline SOC & 10 & 212.48 & 7.63 & 34.84 & 7.63 & - & 262.57 & 26.26 \\
\hline $\begin{array}{l}\text { Total: } \\
\text { Study costs }\end{array}$ & 46 & 728.42 & 33.45 & 328.83 & 29.36 & 9.00 & $1,129.07$ & \\
\hline $\begin{array}{l}\% \text { of total } \\
\text { costs }\end{array}$ & & $64.52 \%$ & $2.96 \%$ & $29.12 \%$ & $2.60 \%$ & $0.80 \%$ & $100.00 \%$ & \\
\hline \multicolumn{9}{|c|}{ Female sex workers } \\
\hline Intervention & 81 & 258.34 & 55.90 & 893.60 & 42.28 & 30.00 & $1,280.12$ & 15.80 \\
\hline $\begin{array}{l}\text { Enhanced } \\
\text { SOC }\end{array}$ & 46 & 258.34 & 35.08 & 160.29 & 35.08 & - & 488.79 & 10.63 \\
\hline $\mathrm{SOC}$ & 43 & 210.49 & 32.79 & 149.83 & 32.79 & - & 425.90 & 9.90 \\
\hline $\begin{array}{l}\text { Total: } \\
\text { Study costs }\end{array}$ & 170 & 727.17 & 123.77 & $1,203.72$ & 110.15 & 30.00 & $2,194.81$ & \\
\hline $\begin{array}{l}\% \text { of total } \\
\text { costs }\end{array}$ & & $33.13 \%$ & $5.64 \%$ & $54.84 \%$ & $5.02 \%$ & $1.37 \%$ & $100.00 \%$ & \\
\hline
\end{tabular}

\subsubsection{Cost-effectiveness results}

For the trucker sample, the enhanced SOC was not an effective or cost-effective alternative to the SOC arm. The intervention arm was the most cost-effective for the trucker sample, driven primarily by the increased number of testers. The ICER of the intervention and enhanced SOC arms was USD -0.58/1. Similarly, the intervention arm was the most cost-effective option for FSWs, with an ICER of USD 0.15 per additional client tested. The intervention arm is the most cost-effective option across the three 
study arms for both population samples; however, it is far more cost-effective for the FSW sample due to the greater number who tested.

The CEA framework was determined to be robust to changes for the majority of significant cost drivers and parameters, except for changes to outcomes, the cost of HIV self-test kits and the supporting costs of sending SMS messages.

Table 14: The ICERs across study arms, truck drivers and female sex workers

\begin{tabular}{|c|c|c|c|c|c|c|}
\hline & & $\begin{array}{l}\text { Cost per } \\
\text { client (USD) }\end{array}$ & Outcomes & $\begin{array}{l}\text { Change in } \\
\text { cost (USD) }\end{array}$ & $\begin{array}{l}\text { Change in } \\
\text { outcome }\end{array}$ & $\begin{array}{l}\text { ICER } \\
\text { (USD) }\end{array}$ \\
\hline \multirow{3}{*}{$\begin{array}{l}\text { Truck } \\
\text { drivers }\end{array}$} & SOC & 26.26 & 10 & - & - & - \\
\hline & $\begin{array}{l}\text { Enhanced } \\
\text { SOC }\end{array}$ & 30.80 & 10 & 4.54 & 0 & - \\
\hline & Intervention & 21.48 & 26 & -9.32 & 16 & -0.58 \\
\hline \multirow{3}{*}{$\begin{array}{l}\text { Female } \\
\text { sex } \\
\text { workers }\end{array}$} & SOC & 9.90 & 43 & - & - & - \\
\hline & $\begin{array}{l}\text { Enhanced } \\
\text { SOC }\end{array}$ & 10.63 & 46 & 0.72 & 3 & 0.24 \\
\hline & Intervention & 15.80 & 81 & 5.18 & 35 & 0.15 \\
\hline
\end{tabular}

\subsubsection{Sensitivity analysis}

The sensitivity analysis is presented in Table 15. It revealed that a lower average monthly salary (by 43.98 per cent) reduced the cost per client across all study arms by approximately USD 0.5 , while the ICER for the enhanced SOC and intervention remained the same. The same effect was observed in reverse when implementing a 40.07 per cent increase in salaries.

Spending an extended period of time with clients (45 minutes) increased the cost per client by USD 0.58 across the SOC and enhanced SOC study arms, compared with a USD 0.13 increase in the intervention arm. The ICER for the intervention became more cost-effective by USD 0.03 . Doubling the average HTC timeframe to 60 minutes increased the cost per client by USD 0.58 across the SOC and enhanced SOC, and by USD 0.34 for the intervention arm. The ICER decreased by a further USD 0.01 for the intervention arm.

Because the cost of an HIV self-test kit was a key driver in the costs of the intervention, sensitivity analysis on this parameter had a large effect on the cost-effectiveness of the intervention. Changing the cost to USD 5.00 decreased the cost per client tested and the ICER for the intervention arm by USD 3.25 and USD 0.20 , respectively. Further decreasing the cost to USD 2.00 resulted in a USD 5.56 decrease in the cost per client as well as a USD 0.35 decrease in the ICER for the intervention arm.

Sensitivity analysis on whether self-testing is supervised or not, revealed a difference in cost. Removing the supervisory costs resulted in a decrease of USD 2.07 and USD 0.13 in the cost per client and ICER of the intervention arm, respectively.

Assuming a discount rate of 3 per cent decreased the cost per client by USD 0.35 across the SOC and enhanced SOC, and by USD 0.30 in the intervention arm, but has no effect on the ICERs. 
Removing the supporting costs (staff time) associated with effecting Activity A (SMS intervention) resulted in decreases of USD 8.68, USD 10.54 and USD 4.06 in the cost per client in the SOC, enhanced SOC and intervention arms, respectively. The ICERINT increased by USD 0.41 due to the decreased cost per client of the enhanced SOC relative to the intervention.

Table 15: Sensitivity analysis of ICER determinants

\begin{tabular}{|c|c|c|c|c|c|c|c|}
\hline & & \multicolumn{2}{|c|}{ Average salary } & \multicolumn{2}{|c|}{ Minimum salary } & \multicolumn{2}{|c|}{ Maximum salary } \\
\hline & & $\begin{array}{l}\text { Cost per } \\
\text { client } \\
\text { (USD) }\end{array}$ & $\begin{array}{l}\text { ICER } \\
\text { (USD) }\end{array}$ & $\begin{array}{l}\text { Cost per } \\
\text { client } \\
\text { (USD) }\end{array}$ & $\begin{array}{l}\text { ICER } \\
\text { (USD) }\end{array}$ & $\begin{array}{l}\text { Cost per } \\
\text { client } \\
\text { (USD) }\end{array}$ & $\begin{array}{l}\text { ICER } \\
\text { (USD) }\end{array}$ \\
\hline \multirow{3}{*}{ Salary } & SOC & 26.26 & - & 25.75 & - & 26.72 & - \\
\hline & Enhanced SOC & 30.80 & - & 30.29 & - & 1.26 & - \\
\hline & Intervention & 21.48 & -0.58 & 20.99 & -0.58 & 21.93 & -0.58 \\
\hline & & \multicolumn{2}{|c|}{30 minutes } & \multicolumn{2}{|c|}{45 minutes } & \multicolumn{2}{|c|}{60 minutes } \\
\hline \multirow{4}{*}{$\begin{array}{l}\text { Time taken } \\
\text { for testing }\end{array}$} & SOC & 26.26 & - & 26.83 & - & 26.83 & - \\
\hline & Enhanced SOC & 30.80 & - & 31.37 & - & 31.37 & - \\
\hline & Intervention & 21.48 & -0.58 & 21.61 & -0.61 & 21.82 & -0.60 \\
\hline & & \multicolumn{2}{|c|}{ Test kit $=$ USD 9.22} & \multicolumn{2}{|c|}{$\begin{array}{l}\text { Test kit = USD } \\
5.00\end{array}$} & \multicolumn{2}{|c|}{$\begin{array}{l}\text { Test kit = USD } \\
2.00\end{array}$} \\
\hline \multirow{4}{*}{$\begin{array}{l}\text { Price of HIV } \\
\text { self-test kit }\end{array}$} & SOC & 26.26 & - & 26.26 & - & 26.26 & - \\
\hline & Enhanced SOC & 30.80 & - & 30.80 & - & 30.80 & - \\
\hline & Intervention & 21.48 & -0.58 & 18.23 & -0.79 & 15.93 & -0.93 \\
\hline & & \multicolumn{2}{|c|}{ Supervised } & \multicolumn{2}{|c|}{ Unsupervised } & & \\
\hline \multirow{4}{*}{$\begin{array}{l}\text { Supervised } \\
\text { versus } \\
\text { unsupervised } \\
\text { testing }\end{array}$} & SOC & 26.26 & - & 6.26 & - & & \\
\hline & Enhanced SOC & 30.80 & - & 30.80 & - & & \\
\hline & Intervention & 21.48 & -0.58 & 19.41 & -0.71 & & \\
\hline & & \multicolumn{2}{|c|}{$\begin{array}{l}\text { Discount rate = } \\
10.67 \%\end{array}$} & \multicolumn{2}{|c|}{$\begin{array}{l}\text { Discount rate }= \\
3.00 \%\end{array}$} & & \\
\hline & SOC & 26.26 & - & 25.90 & - & & \\
\hline \multirow[t]{3}{*}{ Discount rate } & Enhanced SOC & 30.80 & - & 30.44 & - & & \\
\hline & Intervention & 21.48 & -0.58 & 21.18 & -0.58 & & \\
\hline & & \multicolumn{2}{|c|}{$\begin{array}{l}\text { With supporting } \\
\text { costs }\end{array}$} & \multicolumn{2}{|c|}{$\begin{array}{l}\text { Without } \\
\text { supporting costs }\end{array}$} & & \\
\hline \multirow{3}{*}{$\begin{array}{l}\text { Supporting } \\
\text { costs }\end{array}$} & SOC & 26.26 & - & 17.58 & - & & \\
\hline & Enhanced SOC & 30.80 & - & 20.26 & - & & \\
\hline & Intervention & 21.48 & -0.58 & 17.43 & -0.18 & & \\
\hline
\end{tabular}

\subsubsection{Scenario analysis}

From the sensitivity analysis, this study postulated a scenario in which the cost per client tested and the resulting ICERs were considerably lower, using realistic assumptions drawn from the literature reviewed. The results of this scenario analysis are depicted in Table 16. 
Table 16: Scenario analysis of ICER determinants

\begin{tabular}{|l|c|r|l|l|l|l|}
\hline \multirow{2}{*}{} & \multicolumn{2}{|l|}{ Actual outcomes } & \multicolumn{2}{l|}{$\begin{array}{l}\text { 65\% Intervention } \\
\text { response }\end{array}$} & \multicolumn{2}{l|}{$\begin{array}{l}\text { 70\% Intervention } \\
\text { response }\end{array}$} \\
\cline { 2 - 7 } & $\begin{array}{l}\text { Cost per } \\
\text { client (USD) }\end{array}$ & $\begin{array}{l}\text { ICER } \\
\text { (USD) }\end{array}$ & $\begin{array}{l}\text { Cost per } \\
\text { client (USD) }\end{array}$ & $\begin{array}{l}\text { ICER } \\
\text { (USD) }\end{array}$ & $\begin{array}{l}\text { Cost per } \\
\text { client (USD) }\end{array}$ & $\begin{array}{l}\text { ICER } \\
\text { (USD) }\end{array}$ \\
\hline SOC & 26.26 & - & 5.54 & & 5.54 & \\
\hline $\begin{array}{l}\text { Enhanced } \\
\text { SOC }\end{array}$ & 30.80 & - & 5.64 & 0.01 & 5.64 & 0.0145 \\
\hline Intervention & 21.48 & -0.58 & 7.21 & 0.04 & 6.53 & 0.0075 \\
\hline
\end{tabular}

An HIV self-test kit price of USD 2.00 was assumed (Cambiano et al. 2015; WHO 2017), along with an 80 per cent preference for HIV self-testing in the intervention arms (Choko et al. 2011; Jamil et al. 2017). The enhanced SOC response rate is increased to $55 \%$ (De Tolly et al. 2012), while that of the intervention arm increased first to $55 \%$ and then $60 \%$ (De Tolly et al. 2012). The ratio of in-clinic to home-based self-tests was maintained from the actual outcomes of the RCT (7:3). From the results above, the costeffectiveness threshold of the intervention for the assumed values lies somewhere between a response rate of $65 \%$ and $70 \%$ in the intervention arm if the SOC is at $55 \%$.

\section{Discussion}

HIV testing in these samples at baseline was very low, with only 26.9 per cent of truckers and 35.3 per cent of FSWs having had an HIV test in the past year. Testing rates overall during study follow-up were also low, at about 1 per cent of truckers and 6 per cent of sex workers in both the enhanced and traditional SOC arms.

Advertising self-test kits increased HIV testing rates to 3.5 per cent among truckers and 10.8 per cent among FSWs, and thus the increase was statistically significant. This is not very different from the increase in HIV testing at first offer of testing following randomization that we found when recruiting truckers from the waiting room of two North Star Alliance clinics in Kenya. In that study, most had HIV tested recently (median time since previous test was less than six months) and only 8.2 per cent had never tested before.

Those in the intervention arm in which self-testing was offered as a choice had 2.8 times higher odds of testing compared with those in the SOC arm (Kelvin et al. 2017a; b). Thus, the relative increase in testing rate is fairly consistent across the two studies, which differed in terms of how the self-test was initially introduced (by the counselor when the client was already in the clinic versus via text message) and in terms of HIV testing history of the participants.

It is interesting that this size of effect was similar among our sample of infrequent HIV testers and among the sample in our previous study who had tested more recently. However, the absolute difference in testing rates differed widely between the two groups (2.2 per 100 more truckers and 4.7 per 100 more FSWs testing in this study versus 14.9 per 100 people in the previous study) because in this study the baseline (or SOC) testing rate was very low. The higher baseline testing rate among the FSWs and the greater impact of the intervention in this group may be due to the fact that the sex workers work 
close to the clinics in local hotspots (the clinics are located near hotspots by design), as well as the possibility that sex workers have a higher perception of risk than truckers due to their profession.

Our use of text messaging in this study to advertise the availability of a new HIV testing option is also an important innovation that could be useful as countries roll out selftesting in various venues. HIV self-testing was initiated in Kenya in May 2017, a month after our study ended, with plans to make it available at public and private clinics and in pharmacies for a low cost of about USD 8.00 (UNAIDS 2017). Text messages could be used to inform the public as the test kits become available in new locations. Our text message was fairly simple, due to the character limits set for text messages, but now OraQuick has a video and package insert available online in multiple African languages, including Kiswahili (OraSure Technologies 2017). With the increasing proliferation of smartphones in Kenya (Pew Research Center 2015), the link could be sent to people so they can see what the self-test is and how it works. Providing more information about the self-test might lead to a further increase in test uptake over what we achieved with such a simple message.

Despite the success of our intervention, the percentage testing even under the intervention remained alarmingly low (3.5\% of truckers and $10.8 \%$ of FSWs in the intervention arm). Clearly, offering self-testing at North Star Alliance clinics is only a partial solution to the low HIV testing rates among some truckers and FSWs. Other mechanisms will also be needed to increase testing rates in these important populations.

One possible barrier may be the distribution mechanism. Distributing test kits through clinics may not reach those who are unable to access or do not feel comfortable going to clinics. Although everyone in our study had received services from the North Star Alliance clinic system at least once in the past, as indicated by their registration in the medical record system, some may have gotten those services via outreach instead of visiting a clinic.

Other studies have looked at secondary distribution mechanisms for getting self-test kits to people. One study in Kenya compared HIV testing rates among male partners of women recruited in antenatal care clinics when the women were given self-test kits to give their partners for home use versus the standard of care in which women gave their partners a letter referring them to a clinic for standard HIV testing. In that study, the HIV testing rate among the male partners was 1.76 times higher in the intervention group, $51.7 \%$ among the SOC arm versus $90.8 \%$ in the intervention arm (Masters et al. 2016).

A study in Uganda that also distributed self-test kits to male partners via women recruited from antenatal clinics found an increase in HIV testing among those male partners of 2.1 times (risk difference of 38 per 100 men) (Pebody 2017a). Another study conducted door-to-door HIV testing in Zambia and found that offering a choice between the standard provider-administered blood-based HIV test and an oral self-test kit increased testing rates from $55.1 \%$ to $60.4 \%$ (1.1 relative risk and 5.3 per 100 absolute risk difference) (Pebody 2017a).

Two studies conducted in Uganda and Zambia compared HIV test uptake among FSWs when they were (1) offered HIV self-test kits distributed via peer educators; (2) given a 
coupon that could be redeemed for a self-test kit at a clinic; or (3) offered the SOC in which the peer educator provided information about how provider-administered HIV testing can be accessed. In those studies, the testing rates were $100 \%, 97 \%$ and $87 \%$ in Uganda and $95 \%, 84 \%$ and $89 \%$ in Zambia for each of the three groups, respectively. Thus, direct distribution had a greater impact than a coupon-based clinic distribution system (Pebody 2017b).

This suggests that different distribution methods among truckers and sex workers who are infrequent HIV testers should be explored. The North Star Alliance does outreach at truck stops and this might be a mechanism to conveniently distribute self-test kits.

Because a goal of our study was to see if advertising the self-test kits would bring more truckers to the clinics to test, we did not take the test kits to outreach events. Demand creation may also be needed to reach some North Star Alliance clients with HIV testing, as well as those who are not accessing care in North Star or other clinic systems.

Among those in the intervention arm who were offered HIV testing choices, there was a range from which test participants selected. While the majority chose to self-test $(64.5 \%$ and $60.5 \%$ for truckers and FSWs, respectively), the SOC test was chosen by over a third of participants; and of those who chose to self-test, about two thirds chose to do so in the clinic with supervision, while one third chose to take a test kit for home use. This suggests that people vary in their preferences around HIV testing and by offering choices we may increase the chance that one of the options is acceptable.

Our previous self-testing study among truckers in Kenya found similarly varied choices (Kelvin et al. 2017c), as did the Zambian study in which home-based HIV testing choices were offered door to door (home-based provider test only versus home-based testing choices including self-testing with and without supervision) (Pebody 2017a). The fact that a sizeable proportion chose to self-test in the clinic with supervision both in our two studies and in the Zambian study warrants further exploration. It could be that some wanted guidance for their first-time self-testing and going forward they would take a test kit to use at home; or it could also be that some people preferred an oral test over a blood test and preferred provider administration and supervised oral self-testing was the closest they could get to their ideal test in these studies.

A discrete choice experiment we conducted in our previous study among truckers suggested that people have strong preferences regarding blood versus oral and the form of counseling (in-person versus over the phone). These differed by HIV testing history, but preferences regarding who administers the HIV test, as well as the testing location, were not strong (Strauss et al. 2017; Kelvin et al. 2017a). Thus, future studies might explore different combinations of test choices, such as provider-administered oral tests and self-administered blood tests, to try to assess which tests are the most popular and what the array of testing choices should be in order to maximize test uptake.

The cost analysis found that the intervention was substantially more costly compared with the SOC and enhanced SOC, but the main driver of this additional cost was the test kit. The price of OraQuick HIV self-test kits in Kenya has since been reduced to USD 2.00 , about a quarter of what we paid, with an agreement between the Gates Foundation and OraSure Technologies (WHO 2017). This should bring the cost of the intervention much closer to that of the SOC. Furthermore, we found that the number of text 
messages sent (one versus three) made no difference in the comparison between the SOC and enhanced SOC, suggesting that we might get similar increased test uptake from the intervention if we sent only one text message announcing the availability of selftest kits, which would further reduce costs. Importantly, despite the higher cost of the intervention, it was found to be the most cost effective of the three programs due to the higher uptake of HIV testing.

There are a number of limitations to this study that should be considered in its interpretation. First, as mentioned before, our text message was not very detailed and we were unable to pilot test the intervention due to time constraints. Therefore, many receiving it may not have understood what it meant or not known what the self-test was. This may have limited the number of participants who came to the clinics for the self-test and weakened the potential impact offering self-testing as a choice might have had on testing rates.

Second, our method of selection of eligible participants via the North Star Alliance medical record system might have led us to include some who were not really eligible and to exclude some who were eligible due to data errors in the system. The large number of duplicate phone numbers in the system, as well as the missing HIV-testing data on 5 truckers and 38 sex workers who self-tested, indicates a fairly high level of delayed data entry or error in the system. It is also possible that some included in our sample had recently tested or been diagnosed with HIV in a non-North Star Alliance clinic or tested for HIV during follow-up at a non-North Star Alliance clinic and were thus misclassified in our data.

Importantly, the proportion who used the SOC test in the intervention arm was similar to that in the SOC arms $(11 / 750=1.5 \%$ versus $10 / 748=1.3 \%$ and $10 / 762=1.3 \%$ among truckers and $47 / 750=6.3 \%$ versus $46 / 750=6.1 \%$ and $43 / 696=6.2 \%$ among $\mathrm{FSWs}$ in the intervention, enhanced SOC and SOC arms respectively). This suggests that the preference for and willingness to test with the SOC test at a North Star Alliance clinic is similar among all groups, which likely also indicates that willingness or preference to use this same test at a non-North Star Alliance clinic is also similar. Therefore, the error in misclassifying the outcome due to testing at other clinics is likely non-differential by study arm and would bias our results toward the null.

Even if more participants in the SOC arms tested at other clinics than in the intervention arm, that difference would have to be large to wipe out the difference in HIV test uptake that we found, which seems unlikely. In addition, the HIV testing rate following a text message we used to estimate our sample size needs (58\% among truck drivers and $48 \%$ among FSWs) was substantially higher than what we found in our study. This is likely due to differences in the eligibility criteria.

North Star Alliance sends text messages to those who have no documentation of an HIV test in the past three months. In our study, we selected those who not only had not tested in the past 3 months but who also were not regular HIV testers (as measured by their not having tested 4 times in the past 12 months). This may explain why the testing rate in our SOC groups was much lower than that used in the sample size estimates. Fortunately, we still had sufficient statistical power to find the difference between the intervention and enhanced SOC groups to be statistically significant. Furthermore, it is 
possible that the increased testing rate among those in the intervention is partly due to curiosity about a new HIV test and over time the differences in testing rates may decline after self-testing becomes available. Longer follow-up studies are needed to assess the long-term impact of self-testing on testing rates and test frequency.

Finally, our results cannot be generalized to all truckers and sex workers in Kenya, let alone outside Kenya, as we selected a sample that met specific criteria and from a clinicbased medical record system. Those who do not access healthcare at all may differ in important ways that impact HIV testing.

\section{Specific findings for policy and practice}

We found that sending text messages announcing the availability of HIV self-test kits at North Star Alliance clinics in Kenya increased HIV testing rates among male truckers and FSWs who were inconsistent HIV testers. While the cost of this intervention was much higher than that of the SOC, it was found to be the most cost effective of the three programs included in the study. With the reduction of the cost of HIV self-test kits and the need to send fewer text messages, the widespread roll-out of HIV self-testing in North Star Alliance and other clinic systems seems feasible and highly cost effective.

However, a number of considerations need to be made in designing a clinic-based program that includes self-testing. First and foremost, oral self-testing should be thought of as complementary to existing services rather than replacing them. Many of the participants in our study chose the existing SOC HIV test when given a choice, but for others self-testing was an attractive alternative, so much so that more people came to the clinic to test when learning about the availability of self-test kits. Thus, testing choices may be the key to maximizing HIV testing rates.

Implementing oral self-testing not only requires HTC counselor training and consideration of how self-testing fits into the current service model (e.g. costs and pricing, dissemination venues), but it is critical to design appropriate information and counseling resources for clients. As we learned in this and our other study, questions do come up during the testing process, so clients need to have some way to have their questions answered. For those with smartphones, an online video may help (OraSure Technologies 2017).

Offering or even requiring supervision the first time someone self-tests might be another option to ensure that people get their questions answered and feel confident in their ability to self-test in the future. Most of those who self-tested in our study chose to do so in the clinic with supervision even though it was not required, suggesting this is an acceptable option for many as they learn to self-test. Similarly, mechanisms for pre- and post-test counseling need to be established. Mandatory pre-test counseling might be combined with picking up self-test kits at a local clinic or pharmacy, but post-test counseling is more difficult to deliver because it depends on the client seeking out this service. In our study, about a quarter of participants who self-tested at home did not contact the HTC counselor for post-test counseling. Given the challenge of linkage to care for those who test in a clinic setting, some thought about program development and evaluation will be needed to ensure that those who self-test are not even less likely to link to care when they need it. 
However, another concern policymakers may have regarding self-testing is that without some mandatory post-test counseling mechanism through which providers can gather data on the test result, the quality of national data on HIV testing and prevalence may deteriorate or at the very least be less verifiable and thus questioned. If self-testing becomes widespread, as we hope it will, but national statistics only receive test result data from those who take the initiative to contact HIV care providers upon a positive selftest result, there will have to be some effort made to validate HIV testing and prevalence estimates, which could be costly.

One option might be for self-testers to be required to contact the provider from whom they received the self-test kit after testing, as we did in our study, coupled with phonebased follow-up for those who fail to do so. This process would require sufficient staff to take phone calls from self-testers and conduct follow-up. However, an automated system could also be set up in which the caller indicates their test result, which is recorded, and then the caller receives a recorded post-test counseling message with the option to speak with a counselor at any time if they desire. Even so, follow-up calls and possibly other contact methods will still be needed to reach those who fail to call in, as we saw in our study.

Thus policymakers have a number of considerations to make before self-testing is rolled out in clinic systems such as the North Star Alliance, and that roll-out should be done in a considered manner, coupled with evaluation of the various policy and programmatic options in an effort to design policies and programs that can have the greatest impact on HIV testing rates while maintaining or improving linkage to care rates and the quality of the data on HIV testing and HIV incidence and prevalence. However, results from our study and the growing body of empirical evidence on self-testing suggest that it is time to start designing these programs and incorporating self-testing into clinic services. 


\section{References}

Progressio, 2013. HIV in Zimbabwe: Tales of a truck driver, [online]. London, UK: Progressio. Available at: <http://www.progressio.org.uk/blog/ground/hiv-zimbabwe-talestruck-driver> [Accessed 18 June 2014].

IRIN, 2013. Tackling HIV on Kenya's transport corridors, [online]. Nairobi, Kenya: IRIN. Available at: <http://www.irinnews.org/printreport.aspx?reportid=98343> [Accessed 15 June 2014].

Abdool-Karim, Q and Abdool-Karim, SS, 2002. The evolving HIV epidemic in South Africa. Int J Epidemiol, 31(1), pp.37-40.

Azuonwu, O, Erhabor, O and Frank-Peterside, N, 2011. HIV infection in long-distance truck drivers in a low income setting in the Niger Delta of Nigeria. $J$ Community Health, 36(4), pp.583-87.

Bwayo, JJ, Omari, AM, Mutere, AN, Jaoko, W, Sekkade-Kigondu, C, Kreiss, J and Plummer, FA, 1991a. Long distance truck-drivers: 1. Prevalence of sexually transmitted diseases (STDs). East Afr Med J, 68(6), pp.425-9.

Bwayo, JJ, Mutere, AN, Omari, MA, Kreiss, JK, Jaoko, W, Sekkade-Kigondu, C and Plummer, FA, 1991b. Long distance truck drivers: 2. Knowledge and attitudes concerning sexually transmitted diseases and sexual behaviour. East Afr Med J, 68(9), pp.714-9.

Cambiano, V, Ford, D, Mabugu, T, Napierala Mavedzenge, S, Miners, A, Murungi, O, Nakawa, F, Revill, P and Phillips, A, 2015. Assessment of the potential impact and costeffectiveness of self-testing for HIV in low-income countries. J Infect Dis, 212(4), pp.57077.

Chanda, M, Ortblad, K, Mwale, M, Chongo, S, Kanchele, C, Kamungoma, N, Fullem, A, Dunn, C, Barresi, L, Harling, G, Bärnighausen, T and Oldenburg, C, 2017. HIV selftesting among female sex workers in Zambia: a randomized controlled trial (MOAX0105LB). 9th IAS Conference on HIV Science Paris, France 23-26 July 2017 Abstract Book. Geneva, Switzerland: International AIDS Society.

Choko, AT, Desmond, N, Webb, EL, Chavula, K, Napierala-Mavedzenge, S, Gaydos, CA, Makombe, SD, Chunda, T, Squire, SB, French, N, Mwapasa, V and Corbett, EL, 2011. The uptake and accuracy of oral kits for HIV self-testing in high HIV prevalence setting: a cross-sectional feasibility study in Blantyre, Malawi. PLoS Med, 8(10), e1001102.

Creese, A and Parker, D, 1994. Cost analysis in primary health care: a training manual for programme managers. Geneva, Switzerland: World Health Organization.

De Tolly, K, Skinner, D, Nembaware, V and Benjamin, P, 2012. Investigation into the use of short message services to expand uptake of human immunodeficiency virus testing, and whether content and dosage have impact. Telemed J E Health, 18(1), pp.18-23. 
Delany-Moretlwe, S, Bello, B, Kinross, P, Oliff, M, Chersich, M, Kleinschmidt, I and Rees, $\mathrm{H}, 2014$. HIV prevalence and risk in long-distance truck drivers in South Africa: a national cross-sectional survey. Int J STD AIDS, 25(6), pp.428-38.

Drummond, M, Schulpher, M, Claxton, K, Stoddart, G and Torrance, G, 2015. Methods for the economic evaluation of health care programmes. New York: Oxford University Press.

FHI 360, 2006. Behavioral surveillance survey round 1-long distance truck drivers, [online]. Available at:

<http://www.fhi360.org/sites/default/files/media/documents/Round\%201\%20\%20BSS\%20Long\%20Distance\%20Truck\%20Drivers.pdf> [Accessed 15 March 2014].

Frank, H, Botao, C, Young, P, Cummings, B, Inguane, C, Sathane, I, Horth, R, Ngale, K, McFarland, W and Raymond, H, 2013. HIV prevalence and prevention behavior among long distance truck drivers passing through a major truck stop in central Mozambique, 2012, [online]. Available at:

$<$ http://globalhealthsciences.ucsf.edu/sites/default/files/content/pphg/posters/truck_IAS.p df> [Accessed 16 June 2014].

Grabbe, K, Menzies, N, Taegtmeyer, M, Emukule, G, Angala, P, Mwega, I, Musango, G and Marum, E, 2010. Increasing access to HIV counseling and testing through mobile services in Kenya: strategies, utilization, and cost-effectiveness. J Acquir Immune Defic Syndr, 54(3), pp.317-23.

Hendriks, M, Kundu, P, Boers, A, Bolarinwa, O, Te Pas, M, Akande, T, Agbede, K, Gomez, G, Redekop, W, Schultsz, C and Tan, S, 2014. Step-by-step guideline for disease-specific costing studies in low- and middle-income countries: a mixed methodology. Global Health Action, 7(23573).

International Labor Organization. 2005. HIVIAIDS in the transport sector of Southern African countries: A rapid assessment of cross-border regulations and formalities, [online]. Available at: <http://www.ilo.org/wcmsp5/groups/public/@ed_protect/@protrav/@ilo_aids/documents/ publication/wcms_116343.pdf> [Accessed 18 June 2014].

Jamil, M, Prestage, G, Fairley, C, Grulich, A, Smith, K, Chen, M, Holt, M, McNulty, A, Bavinton, B, Conway, D, Wand, H, Keen, P, Bradey, J, Kolstee, J, Batrouney, C, Russell, D, Law, M, Kaldor, J and Guy, R, 2017. Effect of availability of HIV self-testing on HIV testing frequency in gay and bisexual men at high risk of infection (FORTH): a waiting-list randomised controlled trial. Lancet HIV, 4(6), e241-e250.

Kelvin, E, Mwai, E, Romo, M, George, G, Govender, K, Mantell, J, Strauss, M, Nyaga, E and Odhiambo, J, 2017a. Evaluating oral HIV self-testing to increase HIV testing uptake among truck drivers in Kenya, [online]. New Delhi, India: International Initiative for Impact Evaluation (3ie). Available at:

<http://www.3ieimpact.org/media/filer_public/2017/07/19/ie64-truck-drivers-kenya.pdf>. [Accessed 18 June 2014] 
Kelvin, EA, George, G, Mwai, E, Nyaga, E, Mantell, JE, Romo, ML, Odhiambo, JO, Starbuck, L and Govender, K, 2017b. Offering self-administered oral HIV testing to truck drivers in Kenya to increase testing: a randomized controlled trial. AIDS Care, pp.1-9.

Kelvin, EA, George, G, Mwai, E, Nyaga, EN, Mantell, JE, Romo, ML, Odhiambo, JO and Govender, K, 2017c. Offering self-administered oral HIV testing as a choice to truck drivers in Kenya: Predictors of uptake and need for guidance while self-testing. AIDS Behav.

Kenya National Bureau of Statistics (KNBS). 2016. Leading Economic Indicators, [online]. Nairobi, Kenya: KNBS. Available at:

<http://www.knbs.or.ke/index.php?option=com_phocadownload\&view=category\&id=131: 2016\&Itemid=599> [Accessed 22 May 2017].

Kopytoff, V, 2014. Big data's dirty problem, [online]. Time, Inc. Available at: <http://fortune.com/2014/06/30/big-data-dirty-problem/> [Accessed 22 November 2017].

Maheswaran, H, Petrou, S, MacPherson, P, Choko, A, Kumwenda, F, Lalloo, D, Clarke, A and Corbett, E, 2016. Cost and quality of life analysis of HIV self-testing and facilitybased HIV testing and counselling in Blantyre, Malawi. BMC Medicine, 14(1), pp.1-12.

Masters, SH, Agot, K, Obonyo, B, Napierala Mavedzenge, S, Maman, S and Thirumurthy, $\mathrm{H}, 2016$. Promoting partner testing and couples testing through secondary distribution of HIV self-tests: A randomized clinical trial. PLoS Med, 13(11), e1002166.

Matama, L, 2013. National HIVIAIDS/STI strategy launched along Kenya transport corridors, [online]. Geneva, Switzerland: International Organization for Migration. Available at: <https://www.iom.int/news/national-hivaidssti-strategy-launched-alongkenya-transport-corridors> [Accessed 4 November 2017].

Musyoki, H, Kellogg, TA, Geibel, S, Muraguri, N, Okal, J, Tun, W, Fisher Raymond, H, Dadabhai, S, Sheehy, M and Kim, AA, 2015. Prevalence of HIV, sexually transmitted infections, and risk behaviours among female sex workers in Nairobi, Kenya: Results of a respondent driven sampling study. AIDS Behav, 19 Suppl 1(S46-58).

National AIDS Control Council of Kenya (NASCOP), 2008. National guicelines for HIV testing and counseling in Kenya, [online]. Nairobi, Kenya: NASCOP. Available at: $<$ http://www.ilo.org/wcmsp5/groups/public/---ed_protect/---protrav/--ilo_aids/documents/legaldocument/wcms_127533.pdf> [Accessed 19 June 2014].

National AIDS Control Council of Kenya (NASCOP), 2014. Kenya AIDS response progress report 2014: Progress towards zero, [online]. Nairobi, Kenya: NASCOP. Available at:

$<$ http://www.unaids.org/sites/default/files/country/documents/KEN_narrative_report_2014 .pdf>. [Accessed 4 November 2017].

North Star Alliance, 2014. North Star Alliance, [online]. Available at: <http://www.northstar-alliance.org/> [Accessed 19 June 2014]. 
Ojo, O, Verbeek, JH, Rasanen, K, Heikkinen, J, Isotalo, LK, Mngoma, N and Ruotsalainen, E, 2011. Interventions to reduce risky sexual behaviour for preventing HIV infection in workers in occupational settings. Cochrane Database Syst Rev, 12, CD005274.

OraSure Technologies, 2017. OraQuick HIV Self-Test, [online]. Bethlehem, PA: OraSure Technologies, Inc. Available at: <http://www.orasure.com/products-infectious/productsinfectious-oraquick-self-test.asp>. [Accessed 13 September 2017].

Ortblad, K., Kibuuka Musoke, D, Ngabirano, T, Nakitende, A, Magoola, J, Kayiira, P, Taasi, G, Barresi, L, Oldenburg, C and Barnighausen, T, 2017. The impact of HIV selftesting on recent testing, status knowledge, and linkage to care among female sex workers in Kampala, Uganda: A randomized controlled trial (MOLBPEC27). 9th IAS Conference on HIV Science Paris, France, 23-26 July 2017 Abstract Book. Geneva, Switzerland: International AIDS Society.

Pebody, R, 2017a. Can self-testing engage 'hard-to-reach' men with HIV testing?, [online]. London, UK: NAM Publications. Available at: <http://www.aidsmap.com/Canself-testing-engage-hard-to-reach-men-with-HIV-testing/page/3159550/> [Accessed 13 September 2017].

Pebody, R, 2017b. High uptake of HIV self-testing by female sex workers in African countries, [online]. London, UK: NAM Publishers. Available at: <http://www.aidsmap.com/page/3159057/> [Accessed 13 September 2017].

Pew Research Center, 2015. Cell phones in Africa: communication lifeline, [online]. Washington, DC: Pew Research Center. Available at: <http://www.pewglobal.org/2015/04/15/cell-phones-in-africa-communication-lifeline/> [Accessed 13 September 2017].

Ramjee, G, Karim, SS and Sturm, AW, 1998. Sexually transmitted infections among sex workers in KwaZulu-Natal, South Africa. Sex Transm Dis, 25(7), pp.346-9.

Regondi, I, George, G and Pillay, N, 2013. HIVIAIDS in the transport sector of southern Africa: Operational challenges, research gaps and policy recommendations. Development Southern Africa, 30 (4-05) pp.616-28.

Strauss, M, George, G, Lansdell, E, Mantell, JE, Govender, K, Romo, M, Odhiambo, J, Mwai, E, Nyaga, EN and Kelvin, EA, 2017. HIV testing preferences among long distance truck drivers in Kenya: a discrete choice experiment. AIDS Care, pp.1-9.

Sweat, M, Gregorich, S, Sangiwa, G, Furlonge, C, Balmer, D, Kamenga, C, Grinstead, O and Coates, T, 2000. Cost-effectiveness of voluntary HIV-1 counselling and testing in reducing sexual transmission of HIV-1 in Kenya and Tanzania. Lancet, 356(9224), pp.113-21.

Tanser, F, Lesueur, D, Solarsh, G and Wilkinson, D, 2000. HIV heterogeneity and proximity of homestead to roads in rural South Africa: an exploration using a geographical information system. Trop Med Int Health, 5(1), pp.40-6. 
Tversky, A and Kahneman, D, 1981. The framing of decisions and the psychology of choice. Science, 211(4481), pp.453-58.

UNAIDS, 2000. Costing guidelines for HIV prevention strategies, [online]. Geneva, Switzerland: Joint United Nations Programme on HIVIAIDS (UNAIDS). Available at: $<$ http://data.unaids.org/publications/irc-pub05/jc412-costguidel_en.pdf> [Accessed 20 November 2017].

UNAIDS, 2017. Kenya launches self-test kits and PrEP, [online]. Geneva, Switzerland: Joint United Nations Programme on HIVIAIDS (UNAIDS). Available at: <http://www.unaids.org/en/resources/presscentre/featurestories/2017/may/20170505_ke ny> [Accessed 11 September 2017].

World Health Organization, 2017. Market and technology landscape HIV rapid diagnostic tests for self-testing, [online]. Geneva, Switzerland: UNITAIDS. Available at:

$<$ http://www.who.int/hiv/pub/vct/hiv-self-testing-2017-thirdedition/en/> [Accessed 4 November 2017]. 


\section{Other publications in the 3ie Impact Evaluation Report Series}

The following reports are available from http://3ieimpact.org/evidencehub/publications/impact-evaluations

Impacts of community stakeholder engagement interventions in Ugandan oil extractives, 3ie Impact Evaluation Report 97. Parker, R, Coleman, E, Manyindo, J, Schultz, B and Mukuru, E, 2019.

The impacts of formal registration of businesses in Malawi, 3ie Impact Evaluation Report 96. Campos, F, Goldstein, M and McKenzie, D, 2019.

Unpacking the determinants of entrepreneurship development and economic empowerment for women in Kenya, 3ie Impact Evaluation Report 95. McKenzie, D, Puerto, S and Odhiambo, F, 2019.

Impacts of key provisions in Ghana's Petroleum Revenue Management Act, 3ie Impact Evaluation Report 94. Edjekumhene, I, Voors, M, Lujala, P, Brunnschweiler, C, Owusu, CK and Nyamekye, A, 2019.

Using information to break the political resource curse in natural gas management in Mozambique, 3ie Impact Evaluation Report 93. Armand, A, Costa, Al, Coutts, A, Vicente, P and Vilela, I, 2019.

Harnessing transparency initiatives to improve India's environmental clearance process for the mineral mining sector, 3ie Impact Evaluation Report 92. Pande, R and Sudarshan, A, 2019.

Impacts of removing user fees for maternal health services on universal health coverage in Kenya, 3ie Impact Evaluation Report 91. Abuya, T, Dennis, M, Matanda, D, Obare, F and Bellows, B, 2018.

Impact of voice reminders to reinforce harvest aggregation services training for farmers in Mali, 3ie Impact Evaluation Report 90. Osei, RD, Dzanku, FM, Osei-Akoto, I, Asante, F, Hodey, LS, Adu, PN, Adu-Ababio, K and Coulibaly, M, 2018.

Impacts of Breakthrough's school-based gender attitude change programme in Haryana, India, 3ie Impact Evaluation Report 89. Jayachandran, S, Jain, T and Dhar, D, 2018.

Hotspot interventions at scale: the effects of policing and city services on crime in Bogotá, Colombia, 3ie Impact Evaluation Report 88. Blattman, C, Green, D, Ortega, D and Tobón, S, 2018.

Impact evaluation of the Philippine Special Program for Employment of Students, 3ie Impact Evaluation Report 87. Beam, E, Linden, L, Quimbo, S and Richmond, H, 2018.

Community-based distribution of oral HIV self-testing kits: experimental evidence from Zambia, 3ie Impact Evaluation Report 86. Hensen, B, Ayles, H, Mulubwa, C, Floyd, S, Schaap, A, Chiti, B, Phiri, M, Mwenge, L, Simwinga, M, Fidler S, Hayes, R, Bond, V and Mwinga, A, 2018. 
Evaluating the economic impacts of rural banking: experimental evidence from southern India, 3ie Impact Evaluation Report 85. Field, E and Pande, R, 2018.

Direct provision versus facility collection of HIV tests: impacts of self-testing among female sex workers in Uganda. 3ie Impact Evaluation Report 84. Ortblad, K, Musoke, DK, Ngabirano, T, Oldenburg, C and Bärnighausen, T, 2018.

Increasing female sex worker HIV testing: effects of peer educators and HIV self-tests in Zambia, 3ie Impact Evaluation Report 83. Chanda, MM, Ortblad, KF, Mwale, M, Chongo, S, Kanchele, C, Kamungoma, N, Fullem, A, Bärnighausen, T and Oldenburg, CE, 2018.

Community delivery of antiretroviral drugs: a non-inferiority matched-pair pragmatic cluster-randomized trial in Dar es Salaam, Tanzania, 3ie Impact Evaluation Report 82. Francis, JM, Geldsetzer, P, Asmus, G, Ulenga, N, Ambikapathi, R, Sando, D, Fawzi, W and Bärnighausen, T, 2018.

Nourishing the future: targeting infants and their caregivers to reduce undernutrition in rural China, 3ie Impact Evaluation Report 81. Cai, J, Luo, R, Li, H, Lien, J, Medina, A, Zhou, H and Zhang, L, 2018.

Impacts of the World Food Programme's interventions to treat malnutrition in Niger. 3ie Impact Evaluation Report 80. Brück, T, Ferguson, NTN, Ouédraogo, J and Ziegelhöfer, Z, 2018.

Impact evaluation of the World Food Programme's moderate acute malnutrition treatment and prevention programmes in Sudan. 3ie Impact Evaluation Report 79. Guevarra, E, Mandalazi, E, Balegamire, S, Albrektsen, K, Sadler, K, Abdelsalam, K, Urrea, G and Alawad, S, 2018.

Impact evaluation of WFP's programs targeting moderate acute malnutrition in humanitarian situations in Chad. 3ie Impact Evaluation Report 78. Saboya, M, Rudiger, J, Frize, J, Ruegenberg, D, Rodríguez Seco, A and McMillon, C, 2018.

Improving midday meal delivery and encouraging micronutrient fortification among children in India, 3ie Impact Evaluation Report 77. Shastry, GK, Berry, J, Mukherjee, P, Mehta, S and Ruebeck, H, 2018.

Evaluation of infant development centres: an early years intervention in Colombia, 3ie Impact Evaluation Report 76. Andrew, A, Attanasio, O, Bernal, R, Cordona, L, Krutikova, S, Heredia, DM, Medina, C, Peña, X, Rubio-Codina, M and Vera-Hernandez, M, 2018.

Can the wounds of war be healed? Experimental evidence on reconciliation in Sierra Leone. 3ie Impact Evaluation Report 75. Cilliers, J, Dube, O and Siddiqi, B, 2018.

Impact evaluation of the Menabe and Melaky development programme in Madagascar, 3ie Impact Evaluation Report 74. Ring, H, Morey, M, Kavanagh, E, Kamto, K, McCarthy, N, Brubaker, J and Rakotondrafara, C, 2018.

Impact evaluation of the Smallholder Dairy Commercialization Programme in Kenya, 3ie Impact Evaluation Report 73. Bonilla, J, McCarthy, N, Mugatha, S, Rai, N, Coombes, A and Brubaker, J, 2018. 
Impact and adoption of risk-reducing drought-tolerant rice in India, 3ie Impact Evaluation Report 72. Yamano, T, Dar, MH, Panda, A, Gupta, I, Malabayabas, ML and Kelly, E, 2018.

Poverty and empowerment impacts of the Bihar Rural Livelihoods Project in India, 3ie Impact Evaluation Report 71. Hoffmann, V, Rao, V, Datta, U, Sanyal, P, Surendra, V and Majumdar, S 2018.

How should Tanzania use its natural gas? Citizens' views from a nationwide Deliberative Poll, 3ie Impact Evaluation Report 70. Birdsall, N, Fishkin, J, Haqqi, F, Kinyondo, A, Moyo, M, Richmond, J and Sandefur, J, 2018.

Impact evaluation of the conditional cash transfer program for secondary school attendance in Macedonia, 3ie Impact Evaluation Report 69. Armand, A and Carneiro, P, 2018.

Age at marriage, women's education, and mother and child outcomes in Bangladesh, 3ie Impact Evaluation Report 68. Field, E, Glennerster, R, Nazneen, S, Pimkina, S, Sen, I and Buchmann, N, 2018.

Evaluating agricultural information dissemination in western Kenya, 3ie Impact Evaluation Report 67. Fabregas, R, Kremer, M, Robinson, J and Schilbach, F, 2017.

General equilibrium impact assessment of the Productive Safety Net Program in Ethiopia, 3ie Impact Evaluation Report 66. Filipski, M, Taylor, JE, Abegaz, GA, Ferede, T, Taffesse, AS and Diao, X, 2017.

Impact of the Uddeepan programme on child health and nutrition in India, 3ie Impact Evaluation Report 65. Kochar, A, Sharma, A and Sharma, A, 2017.

Evaluating oral HIV self-testing to increase HIV testing uptake among truck drivers in Kenya, 3ie Impact Evaluation Report 64. Kelvin, EA, Mwai, E, Romo, ML, George, G, Govender, K, Mantell, JE, Strauss, M, Nyaga, EN and Odhiambo, JO, 2017.

Integration of EPI and paediatric HIV services for improved ART initiation in Zimbabwe, 3ie Impact Evaluation Report 63. Prescott, M, Boeke, C, Gotora, T, Mafaune, HW, Motsi, W, Graves, J, Mangwiro, A and McCarthy, E, 2017.

Increasing male partner HIV testing using self-test kits in Kenya, 3ie Impact Evaluation Report 62. Gichangi, A, Korte, JE, Wambua, J, Vrana, C and Stevens, D, 2017.

Evaluating the impact of community health worker integration into prevention of motherto-child transmission of HIV services in Tanzania, 3ie Impact Evaluation Report 61. Nance, N, McCoy, S, Ngilangwa, D, Masanja, J, Njau, P and Noronha, R, 2017.

Using HIV self-testing to promote male partner and couples testing in Kenya, 3ie Impact Evaluation Report 60. Thirumurthy, H, Omanga, E, Obonyo, B, Masters, S and Agot, K, 2017.

Increasing male partner HIV self-testing at antenatal care clinics in Kenya, 3ie Impact Evaluation Report 59. Gichangi, A, Korte, JE, Wambua, J, Vrana, C and Stevens, D, 2017. 
Impact of free availability of public childcare on labour supply and child development in Brazil, 3ie Impact Evaluation Report 58. Attanasio, O, Paes de Barros, R, Carneiro, P, Evans, D, Lima, L, Olinto, P and Schady, N, 2017.

Estimating the effects of a low-cost early stimulation and parenting education programme in Mexico, 3ie Impact Evaluation Report 57. Cardenas, S, Evans, D and Holland, P, 2017.

The Better Obstetrics in Rural Nigeria study: an impact evaluation of the Nigerian Midwives Service Scheme, 3ie Impact Evaluation Report 56. Okeke, E, Glick, P, Abubakar, IS, Chari, AV, Pitchforth, E, Exley, J, Bashir, U, Setodji, C, Gu, K and Onwujekwe, O, 2017.

The Productive Safety Net Programme in Ethiopia: impacts on children's schooling, labour and nutritional status, 3ie Impact Evaluation Report 55. Berhane, G, Hoddinott, J, Kumar, N and Margolies, A, 2016.

The impact of youth skills training on the financial behaviour, employability and educational choice in Morocco, 3ie Impact Evaluation Report 54. Bausch, J, Dyer, P, Gardiner, D, Kluve, J and Mizrokhi, E, 2016.

Using advertisements to create demand for voluntary medical male circumcision in South Africa, 3ie Impact Evaluation Report 53. Frade, S, Friedman, W, Rech, D and Wilson, N, 2016.

The use of peer referral incentives to increase demand for voluntary medical male circumcision in Zambia, 3ie Impact Evaluation Report 52. Zanolini, A, Bolton, C, Lyabola, LL, Phiri, G, Samona, A, Kaonga, A and Harsha Thirumurthy, H, 2016.

Using smartphone raffles to increase demand for voluntary medical male circumcision in Tanzania, 3ie Impact Evaluation Report 51. Mahler, H and Bazant, E, 2016.

Voluntary medical male circumcision uptake through soccer in Zimbabwe, 3ie Impact Evaluation Report 50. DeCelles, J, Kaufman, Z, Bhauti, K, Hershow, R, Weiss, H, Chaibva, C, Moyo, N, Braunschweig, E, Mantula, F, Hatzold, K and Ross, D, 2016.

Measuring the impact of SMS-based interventions on uptake of voluntary medical male circumcision in Zambia, 3ie Impact Evaluation Report 49. Leiby, K, Connor, A, Tsague, L, Sapele, C, Koanga, A, Kakaire, J and Wang, P, 2016.

Assessing the impact of delivering messages through intimate partners to create demand for voluntary medical male circumcision in Uganda, 3ie Impact Evaluation Report 48.

Semeere, AS, Bbaale, DS, Castelnuovo, B, Kiragga, A, Kigozi, J, Muganzi, A, Kambugu, A and Coutinho, AG, 2016.

Optimising the use of economic interventions to increase demand for voluntary medical male circumcision in Kenya, 3ie Impact Evaluation Report 47. Thirumurthy, $\mathrm{H}$, Omanga, E, Rao, SO, Murray, K, Masters, S and Agot, K, 2016. 
The impact of earned and windfall cash transfers on livelihoods and conservation in Sierra Leone, 3ie Impact Evaluation Report 46. Bulte, E, Conteh, B, Kontoleon, A, List, J, Mokuwa, E, Richards, P, Turley, T and Voors, M, 2016.

Property tax experiment in Pakistan: Incentivising tax collection and improving performance, 3ie Impact Evaluation Report 45. Khan, A, Khwaja, A and Olken, B, 2016.

Impact of mobile message reminders on tuberculosis treatment outcomes in Pakistan, 3ie Impact Evaluation Report 44. Mohammed, S, Glennerster, R and Khan, A, 2016.

Making networks work for policy: Evidence from agricultural technology adoption in Malawi, 3ie Impact Evaluation Report 43. Beaman, L, BenYishay, A, Fatch, P, Magruder, $\mathrm{J}$ and Mobarak, AM, 2016.

Estimating the impact and cost-effectiveness of expanding access to secondary education in Ghana, 3ie Impact Evaluation Report 42. Dupas, P, Duflo, E and Kremer, M, 2016.

Evaluating the effectiveness of computers as tutors in China, 3ie Impact Evaluation Report 41. Mo, D, Bai, Y, Boswell, M and Rozelle, S, 2016.

Micro entrepreneurship support programme in Chile, 3ie Impact Evaluation Report 40. Martínez, CA, Puentes, EE and Ruiz-Tagle, JV, 2016.

Thirty-five years later: evaluating the impacts of a child health and family planning programme in Bangladesh, 3ie Impact Evaluation Report 39. Barham, T, Kuhn, R, Menken, J and Razzaque, A, 2016.

Effectiveness of a rural sanitation programme on diarrhoea, soil-transmitted helminth infection and malnutrition in India, 3ie Impact Evaluation Report 38. Clasen, T, Boisson, S, Routray, P, Torondel, B, Bell, M, Cumming, O, Ensink, J, Freeman, M and Jenkins, M, 2016.

Evaluating the impact of vocational education vouchers on out-of-school youth in Kenya, 3ie Impact Evaluation Report 37. Hicks, JH, Kremer, M, Mbiti, I and Miguel, E, 2016.

Removing barriers to higher education in Chile: evaluation of peer effects and scholarships for test preparation, 3ie Impact Evaluation Report 36. Banerjee, A, Duflo E and Gallego, F, 2016.

Sustainability of impact: dimensions of decline and persistence in adopting a biofortified crop in Uganda, 3ie Impact Evaluation Report 35. McNiven, S, Gilligan, DO and Hotz, C 2016.

A triple win? The impact of Tanzania's Joint Forest Management programme on livelihoods, governance and forests, 3ie Impact Evaluation Report 34. Persha, L and Meshack, C, 2016.

The effect of conditional transfers on intimate partner violence: evidence from Northern Ecuador, 3ie Impact Evaluation Report 33. Hidrobo, M, Peterman, A and Heise, L, 2016. 
The effect of transfers and preschool on children's cognitive development in Uganda, 3ie Impact Evaluation Report 32. Gillian, DO and Roy, S, 2016.

Can egovernance reduce capture of public programmes? Experimental evidence from India's employment guarantee, 3ie Impact Evaluation Report 31. Banerjee, A, Duflo, E, Imbert, C, Mathew, S and Pande, R, 2015.

Improving maternal and child health in India: evaluating demand and supply strategies, 3ie Impact Evaluation Report 30. Mohanan, M, Miller, G, Forgia, GL, Shekhar, S and Singh, K, 2016.

Smallholder access to weather securities in India: demand and impact on production decisions, 3ie Impact Evaluation Report 28. Ceballos, F, Manuel, I, Robles, M and Butler, A, 2015.

What happens once the intervention ends? The medium-term impacts of a cash transfer programme in Malawi, 3ie Impact Evaluation Report 27. Baird, S, Chirwa, E, Mclntosh, C and Özler, B, 2015.

Validation of hearing screening procedures in Ecuadorian schools, 3ie Impact Evaluation Report 26. Muñoz, K, White, K, Callow-Heusser, C and Ortiz, E, 2015.

Assessing the impact of farmer field schools on fertilizer use in China, 3ie Impact Evaluation Report 25. Burger, N, Fu, M, Gu, K, Jia, X, Kumar, KB and Mingliang, G, 2015.

The SASA! study: a cluster randomised trial to assess the impact of a violence and HIV prevention programme in Kampala, Uganda, 3ie Impact Evaluation Report 24. Watts, C, Devries, K, Kiss, L, Abramsky, T, Kyegombe, N and Michau, L, 2014.

Enhancing food production and food security through improved inputs: an evaluation of Tanzania's National Agricultural Input Voucher Scheme with a focus on gender impacts, 3ie Impact Evaluation Report 23. Gine, X, Patel, S, Cuellar-Martinez, C, McCoy, S and Lauren, R, 2015.

A wide angle view of learning: evaluation of the CCE and LEP programmes in Haryana, 3ie Impact Evaluation Report 22. Duflo, E, Berry, J, Mukerji, S and Shotland, M, 2015.

Shelter from the storm: upgrading housing infrastructure in Latin American slums, 3ie Impact Evaluation Report 21. Galiani, S, Gertler, P, Cooper, R, Martinez, S, Ross, A and Undurraga, R, 2015.

Environmental and socioeconomic impacts of Mexico's payments for ecosystem services programme, 3ie Impact Evaluation Report 20. Alix-Garcia, J, Aronson, G, Radeloff, V, Ramirez-Reyes, C, Shapiro, E, Sims, K and Yañez-Pagans, P, 2015.

A randomised evaluation of the effects of an agricultural insurance programme on rural households' behaviour: evidence from China, 3ie Impact Evaluation Report 19. Cai, J, de Janvry, A and Sadoulet, E, 2014. 
Impact of malaria control and enhanced literacy instruction on educational outcomes among school children in Kenya: a multi-sectoral, prospective, randomised evaluation, 3ie Impact Evaluation Report 18. Brooker, S and Halliday, K, 2015.

Assessing long-term impacts of conditional cash transfers on children and young adults in rural Nicaragua, 3ie Impact Evaluation Report 17. Barham, T, Macours, K, Maluccio, JA, Regalia, F, Aguilera, V and Moncada, ME, 2014.

The impact of mother literacy and participation programmes on child learning: evidence from a randomised evaluation in India, 3ie Impact Evaluation Report 16. Banerji, R, Berry, J and Shortland, M, 2014.

A youth wage subsidy experiment for South Africa, 3ie Impact Evaluation Report 15. Levinsohn, J, Rankin, N, Roberts, G and Schöer, V, 2014.

Providing collateral and improving product market access for smallholder farmers: a randomised evaluation of inventory credit in Sierra Leone, 3ie Impact Evaluation Report 14. Casaburi, L, Glennerster, R, Suri, T and Kamara, S, 2014.

Scaling up male circumcision service provision: results from a randomised evaluation in Malawi, 3ie Impact Evaluation Report 13. Thornton, R, Chinkhumba, J, Godlonton, S and Pierotti, R, 2014.

Targeting the poor: evidence from a field experiment in Indonesia, 3ie Impact Evaluation Report 12. Atlas, V, Banerjee, A, Hanna, R, Olken, B, Wai-poi, M and Purnamasari, R, 2014.

An impact evaluation of information disclosure on elected representatives' performance: evidence from rural and urban India, 3ie Impact Evaluation Report 11. Banerjee, A, Duflo, E, Imbert, C, Pande, R, Walton, M and Mahapatra, B, 2014.

Truth-telling by third-party audits and the response of polluting firms: Experimental evidence from India, 3ie Impact Evaluation Report 10. Duflo, E, Greenstone, M, Pande, R and Ryan, N, 2013.

No margin, no mission? Evaluating the role of incentives in the distribution of public goods in Zambia, 3ie Impact Evaluation Report 9. Ashraf, N, Bandiera, O and Jack, K, 2013.

Paying for performance in China's battle against anaemia, 3ie Impact Evaluation Report 8. Zhang, L, Rozelle, S and Shi, Y, 2013.

Social and economic impacts of Tuungane: final report on the effects of a communitydriven reconstruction programme in the Democratic Republic of Congo, 3ie Impact Evaluation Report 7. Humphreys, M, Sanchez de la Sierra, R and van der Windt, P, 2013.

The impact of daycare on maternal labour supply and child development in Mexico, 3ie Impact Evaluation Report 6. Angeles, G, Gadsden, P, Galiani, S, Gertler, P, Herrera, A, Kariger, P and Seira, E, 2014. 
Impact evaluation of the non-contributory social pension programme 70 y más in Mexico, 3ie Impact Evaluation Report 5. Rodríguez, A, Espinoza, B, Tamayo, K, Pereda, P, Góngora, V, Tagliaferro, G and Solís, M, 2014.

Does marginal cost pricing of electricity affect groundwater pumping behaviour of farmers? Evidence from India, 3ie Impact Evaluation Report 4. Meenakshi, JV, Banerji, A, Mukherji, A and Gupta, A, 2013.

The GoBifo project evaluation report: Assessing the impacts of community-driven development in Sierra Leone, 3ie Impact Evaluation Report 3. Casey, K, Glennerster, R and Miguel, E, 2013.

A rapid assessment randomised-controlled trial of improved cookstoves in rural Ghana, 3ie Impact Evaluation Report 2. Burwen, J and Levine, DI, 2012.

The promise of preschool in Africa: A randomised impact evaluation of early childhood development in rural Mozambique, 3ie Impact Evaluation Report 1. Martinez, S, Naudeau, S and Pereira, V, 2012. 
In an effort to achieve the UNAIDS 90-90-90 goals, public health officials need innovative ways to target key populations that have been historically hard to reach. Kelvin and colleagues evaluated whether making HIV self-test kits available as a testing option at North Star Alliance roadside wellness clinics in Kenya and advertising via SMS increases HIV testing rates among truckers and sex workers who were irregular testers, compared with sending text messages about HIV testing in general. They find that offering HIV self-testing to high-risk populations like truckers and sex workers and advertising its availability via text message may be a cost-effective way to increase HIV testing rates in these important groups.

\section{Impact Evaluation Series}

International Initiative for Impact Evaluation 202-203, Rectangle One D-4, Saket District Centre New Delhi - 110017 India 